Poverty and Nutrition in Bolivia 

A WORLD BANK COUNTRY STUDY

\section{Poverty and Nutrition in Bolivia}

The World Bank

Washington, D.C. 
(C) 2002 The International Bank for Reconstruction and Development / The World Bank 1818 H Street, NW

Washington, DC 20433

All rights reserved.

1234050403

World Bank Country Studies are among the many reports originally prepared for internal use as part of the continuing analysis by the Bank of the economic and related conditions of its developing member countries and of its dialogues with the governments. Some of the reports are published in this series with the least possible delay for the use of governments and the academic, business and financial, and development communities. The typescript of this paper therefore has not been prepared in accondance with the procedures appropriate to formal printed texts, and the World Bank accepts no responsibility for errors. Some sources cited in this paper may be informal documents that are not readily available.

The findings, interpretations, and conclusions expressed here do not necessarily reflect the views of the Board of Executive Directors of the World Bank or the governments they represent.

The World Bank cannot guarantee the accuracy of the data included in this work. The boundaries, colors, denominations, and other information shown on any map in this work do not imply on the part of the World Bank any judgment of the legal status of any territory or the endorsement or acceptance of such boundaries.

\section{Rights and Permissions}

The material in this work is copyrighted. No part of this work may be reproduced or transmitted in any form or by any means, electronic or mechanical, including photocopying, recording, or inclusion in any information storage and retrieval system, without the prior written permission of the World Bank. The World Bank encourages dissemination of its work and will normally grant permission promptly.

For permission to photocopy or reprint, please send a request with complete information to the Copyright Clearance Center, Inc., 222 Rosewood Drive, Danvers, MA 01923, USA, telephone 978-750-8400, fax 978-750-4470, www.copyright.com.

All other queries on rights and licenses, including subsidiary rights, should be addressed to the Office of the Publisher, World Bank, 1818 H Street NW, Washington, DC 20433, USA, fax 202-522-2422, e-mail pubrights@worldbank.org.

ISBN: 0-8213-5378-0

ISSN: 0253-7494

\section{Library of Congress Catologing-in-Publication Data}

Poverty and nutrition in Bolivia p. cm - (A World Bank country study)

Includes bibliographical references.

ISBN 0-8213-5378-0

1. Poverty-Bolivia. 2. Nutriation-Bolivia. 3. Public healt-Bolivia. 4.

Malnutrition-Bolivia. I. World Bank. II. Series.

RA418.5.P6 P6845 2002

$363.8^{\prime} 0984-\mathrm{dc} 21$ 


\section{Table of Contents}

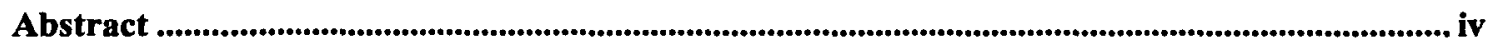

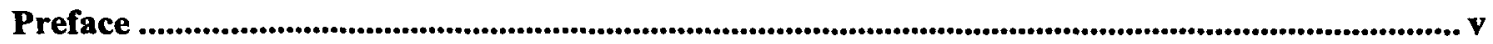

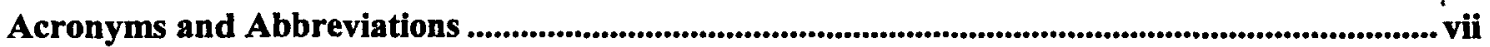

Acknowledgments .......................................................................................................................................... viii

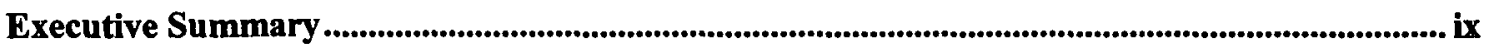

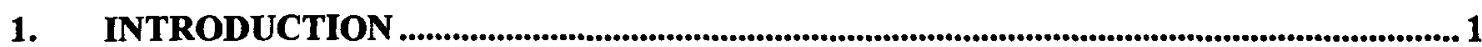

2. THE NUTRITION PROBLEM IN BOLIVIA $\ldots$

THE PREVALENCE OF MALNUTRITION ...................................................................................... 6

MALNUTRITION RELATIVE TO WEALTH, LOCATION, AND ETHNICITY .......................................... 7

THE SOURCES OF MALNUTRTION ....................................................................................

The Keystone of A SOlution: Proper FeEdING of THE Under-Two CHILD........................ 12

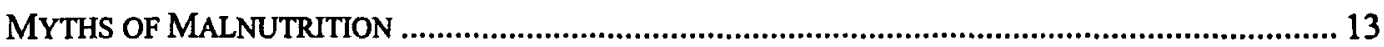

3. THE TARGETING AND DESIGN OF NUTRITION PROGRAMS IN BOLIVIA ........... 17

PRIORITY POPULATION TARGETS ................................................................................................. 18

EFFICIENT NUTRITIONAL INTERVENTIONS ............................................................................. 19

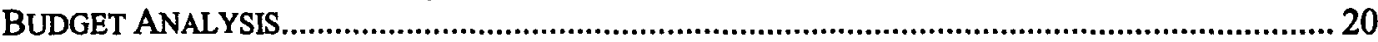

4. THE IMPLEMENTATION AND MANAGEMENT OF NUTRITION PROGRAMS IN

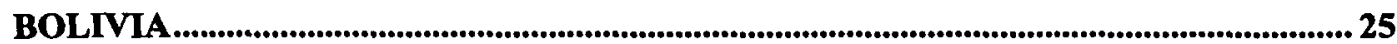

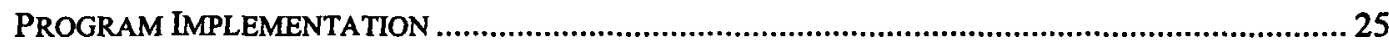

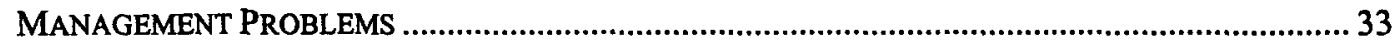

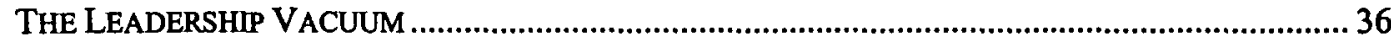

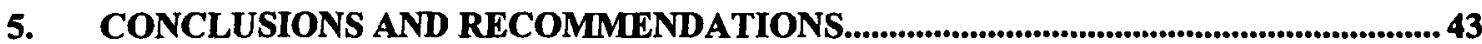

THE WEAKNESSES OF THE NUTRITION RESPONSE................................................................. 43

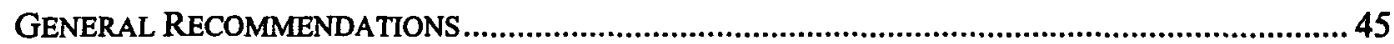

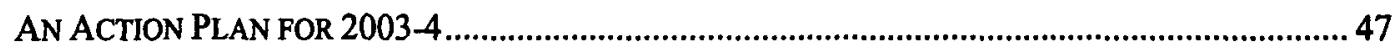

REFERENCES.......................................................................................................................................... 51

FIGURES

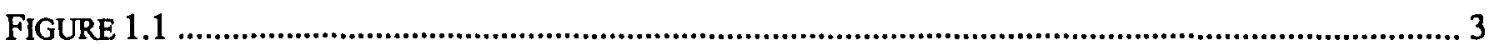

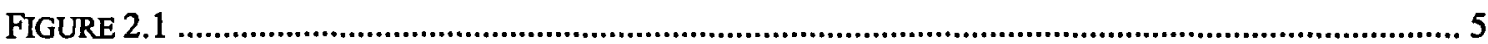

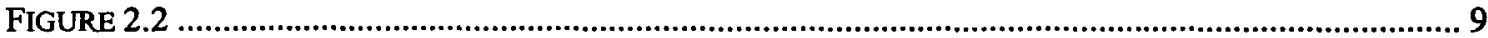

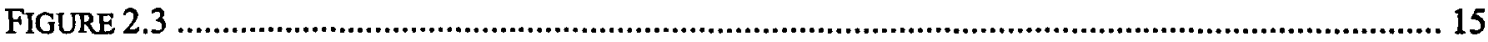

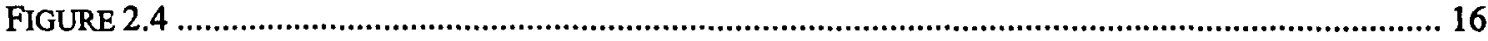

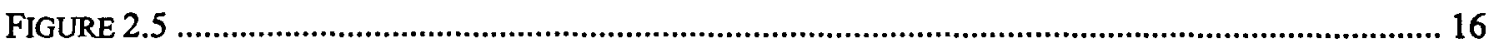

TABLES

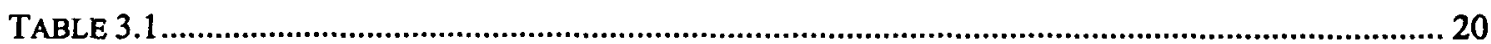

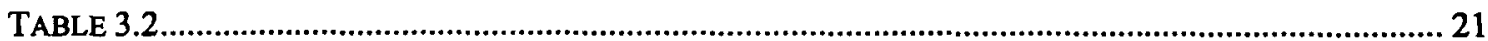

TABLE 3.3

TABLE 3.4

TABLE 3.5

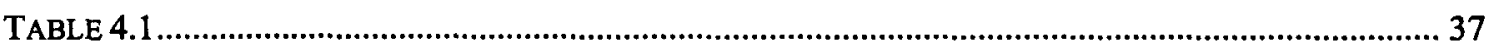


Malnutrition afflicts about one fourth of children under three years of age and between 12 and 24 percent of women in Bolivia. It contributes to high death rates, immune deficiency, learning disabilities, and low work productivity. Malnutrition in Bolivia is caused not so much by lack of food as by lack of purchasing power and by household behaviors toward feeding and caring of young children. Despite considerable resources devoted to addressing the problem - \$67 Million in 2000 alone by the public and NGO sectors - malnutrition has not been decreasing as rapidly as in other countries in Latin America. Most programs which should address the problem are neither targeted to the individuals most in need (poor children under two and pregnant women) nor are they using global best practices. The most effective nutrition programs worldwide are those designed to prevent malnutrition in children under two: community-based growth promotion, food fortification, and iron and vitamin A supplement programs (both facilitybased and community-based). Building on success in eliminating another nutrition problem - iodine deficiency disorders - Bolivia needs to marshal the necessary resources and give political support to addressing the remainder of the problem. This will require dynamic new leadership in nutrition, a practical time-bound and budgeted national nutrition strategy, technical improvement in programs, and oversight by civil society. Capacity strengthening at the municipal level is required to assure that nutrition programs keep pace with decentralization. The Ministry of Health, in particular, needs to improve nutrition education, iron supplementation, and growth promotion. Nutritional status is one of the Millennium Development Goals and should be monitored in Bolivia as a key outcome indicator of the poverty reduction strategy. 


\section{Preface}

Bolivia's First National Dialogue on Poverty, conducted in 1997, established four "pillars" of poverty alleviation: opportunity, equity, institutionality, and dignity. At the conclusion of the dialogue, the government created the Nuevo Marco de Relacionamiento (which in the World Bank became the Comprehensive Development Framework), a process for developing strategies in each of these areas in collaboration with the donors. The framework process addresses each of the four pillars by selecting key indicators, setting targets, evaluating current programs in light of the targets, and modifying programs or targets to make them mutually consistent.

At the Bolivia Consultative Group Meeting in April 1998, the Bolivian government and the donors agreed to track the effectiveness of the country's poverty reduction program by

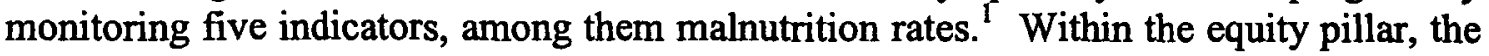
government and donors proposed malnutrition (defined as deficient weight for age among children under three) as an "expanded pillar indicator" and set a goal of reducing such malnutrition to 6.5 percent by [2002].

In September 1999, separate meetings were held in La Paz with representatives of the government, nongovernmental organizations (NGOs), and aid donors to initiate the present study and to gain advice. Attending the meetings were representatives of the major government agencies, donors and of NGO umbrella organizations working in nutrition. All participants in the La Paz meetings agreed that the lack of clear and effective leadership in nutrition was one of the major obstacles to effective action.

In addition, all three groups expressed the strong opinion that any approach to malnutrition needed to be integrated into the decentralization process. Opinions were mixed as to whether to promote free-standing nutrition programs or to incorporate nutrition more effectively into integrated agendas addressing major sectors such as health, education, and agriculture. A nutrition program might attract attention in the budget and receive technical assistance; the reality, however, is that the government and donors invest most of their money in integrated programs that may have nutrition as one of many goals. As documented in this study, much of Bolivia's failure on the nutrition front in recent years is attributable to the failure of the integrated programs to support the nutrition component with strategies that are properly targeted and effective, a lack of trained staff, and the absence of documentation of needs, goals, and results.

In December 1999 the present study began to be formally incorporated into the government poverty-alleviation process when a working group on nutrition made up of donors, NGOs and the major government institutions involved in nutrition was set up as part of the equity pillar. The working group would guide this study, oversee an inventory

1. The other four indicators were the poverty headcount ratio, the poverty gap ratio, maternal mortality, and infant mortality. In addition, the World Bank's Country Assistance Strategy is using malnutrition as an indicator of effectiveness of the World Bank's poverty alleviation programs in Bolivia. 
of nutrition programs, and identify the actions in nutrition that would be most strategic for the alleviation of poverty. The original members of the study's working group were the members of the study's review committee, which was later expanded to include much broader government participation. In July 2000 the working group reconvened to review the inventory and recommend actions in nutrition in a report submitted to the Ministry of Finance, which was preparing the overall poverty strategy report. The working group's efforts were reflected in the government's annual report to donors that was prepared for the September 2000 meeting of the Bolivia Consultative Group and ultimately in the government's 2001 Poverty Reduction Strategy Paper.

The authors of this study consulted with the Bolivian government, donors, and nongovernmental organizations and arranged for a number of studies concerning experiences over the past decade. Among these studies were the Municipal Constraints Assessment (Paulson and Velarde, 2001) and the Micronutrient Constraints Assessment (Lopez, 2001).The Municipal Constraints Assessment was carried out in 15 very poor municipalities covering every department (major administrative unit) in the country. As part of the assessment, community residents, functionaries, and local leaders evaluated Bolivia's nutrition problem and nutrition-related programs. The Micronutrient Constraints Assessment was conducted in health facilities, both public and semiprivate (those in the "social security" system), in nine municipalities in four departments. The assessment included observations, interviews with health facility staff, and interviews with beneficiaries individually and in focus groups.

This study also commissioned reviews of the available information on Bolivia's water and sanitation, sustainable livelihoods, nutrition program evaluations, and nutrition institutions. Much of the data in this study came from a quantitative re-analysis of the 1998 National Demographic and Health Survey and, for selected parts of the country, re-analysis of the 1993 and 1997 evaluations of the Social Fund (Jimenez, 2001; see technical annex). Budget data in this study were provided by government agencies, NGOs, and donors. They were rechecked and investigated if they appeared incomplete or inconsistent, but the accuracy was ultimately the responsibility of the entity providing the data.

For program evaluations, a program was defined as "nutrition-related" if it included nutrition, hunger-alleviation, or increased food consumption as an objective. As a result, some health programs, the PAN program, food security programs, and school feeding were counted as nutrition programs.

Although the report was finished in 2001 it did not complete the review process until 2002 due to turnover of key staff at the World Bank. 


\section{ACRONYMS AND AbBREVIATIONS}

AIPE Education and Promotion Institution's Association (Asociación de Instituciones de Promoción y Educación)

APROSAR Association of Rural Health Promoters (Asociación de Promotores de Salud en Area Rural)

ARI

CRS

DHS

ENDSA

Acute Respiratory Infections

Catholic Relief Services

Demographic and Health Survey

FDC

FIS

Demographic and Health Survey (Encuesta Nacional de Demografia y Salud)

Rural Development Fund (Fondo de Desarrollo Campesino)

HAM

IEC

Social Investment Fund

INE

IMCI

LSMS

MACRO

MCA

MnCA

MOH

Honorable Municipal Mayo's Office (Honorable Alcaldia Municipal)

Information, Education and Communication

National Statistics Institute (Instituto Nacional de Estadística)

Integrated Management of Childhood Illness

Living Standards Measurement Survey

Macro International Inc (Implements Demographic and Health Surveys-

USAID Funding)

Municipal Micronutrient Constraints Assessment

Micronutrient Constraints Assessment

Ministry of Health

NGO

Nongovernmental Organizations

PAN

PROAGRO

PROCOSI

PROFILES

Early-Childhood Development Program (Programa Nacional de Atención a

Niños y Niñas menores de 6 años)

Agricultural Prómoters (Promotores Agropecuarios)

Integral Health Program (Programa de Coordinación en Salud Integral)

Computer Package to present alternative Scenarios in Nutrition (implemented

by Academy for Educational Development in Washington)

PROSALUD Health Protection (Protección a la Salud)

PROMUJER Programas para la Mujer

PRSP

PSF

SNIS

Poverty Reduction Strategy Paper

Family Health Program (Programa de Salud Familiar)

National Health Systems Information (Sistema Nacional de Información en Salud)

SVEN Nutrition Surveillance System (Sistema de Vigilancia en Nutrición)

UDAPE . Analysis and Economic Policy Unit (Unidad de Análisis de Políticas

Económicas)

UDAPSO Analysis and Social Programs Unit (Unidad de Análisis y Programas

Sociales)

UNAP National (personal) Health Services Unit (Unidad Nacional de Atención a las

Personas)

UNICEF United Nations Children's Fund

UNDP

USAID

United Nations Development Program

United States Agency for International Development

WFP

World Food Program

Government Fiscal Year

January 1-December 31 


\section{ACKNOWLEDGMENTS}

The study was written by Judith McGuire and Cynthia Lopez. Members of the Bolivian Government who made significant contributions to the study include Rodney Pereira, Miguel Vera, Rony Narvaez and Wilson Jimenez (UDAPE); Maria Teresa Siles (UNAP); Dr. Fernando Lavadenz (Health Reform Project); Dr. Jaime Telleria, Guillermo Tapia (Ministry of Health and Social Provision). Dr. Anil Deolalikar, University of Washington, assisted in the writing of the economics sections. Gregg Forte was the editor. Background studies were prepared by the following consultants: Nancy Velarde, Susan Paulson, Benjamin Kohl, Ruth Villegas, Monica Crespo, Cecilia de la Vega and Margarita Lovon (Municipal Constraints Assessment), Rae Galloway, Maria Eugenia Lopez and Juana Molina (Micronutrient Constraints Assessment), Wilson Jimenez (Multivariate Analysis), Margarita Lovon (Water and Nutrition), Cindy Lopez, Rosario Alurralde and Albina Torrez (Program Inventory), Giovanni Daza (Program Evaluations), Ana Maria Aguilar and Maria J. Cabrerizo (Insitutional Analysis), German Escobar (Livelihoods Security), and Herbert Weinstein (Food Fortification).

Significant contributions were also made by the following World Bank Staff: John Newman, David Tuchschneider, Monica Claros, Rae Galloway, Quentin Wodon, Daniel Cotlear, Evangeline Javier, Michele Gragnolati, and the peer reviewers (Abdo Yazbeck, Sandra Rosenhouse, Maureen Lewis and Jayshree Balachander).

Cosponsors of the study include USAID, which provided funding for technical assistance; the Micronutrient Initiative; the Development Fund for International Development; Danish, Swedish, Norwegian, and Finnish trust funds at the World Bank; and UNICEF. A special thanks goes to the World Food Program, which financed four of the substudies contributing to this report. Important background work had already been carried out by the European Union Food Security Unit, the UNDP, and the World Bank jointly with government of Bolivia (Poverty Diagnostic, and Rural Productivity Study).

$\begin{array}{ll}\text { Vice President: } & \text { David De Ferranti } \\ \text { Country Director : } & \text { Isabel Guerrero } \\ \text { Sector Director : } & \text { Ana-Maria Arriagada } \\ \text { Sector Specialist: } & \text { Evangeline Javier } \\ \text { Task Manager: } & \text { Judith McGuire/Michele Gragnolati }\end{array}$




\section{EXECUTIVE SUMMARY}

Malnutrition is crippling Bolivia, afflicting about one in four babies born there each year and reducing its potential for economic growth. Despite high annual expenditures on improving nutrition and food security in Bolivia-by this study's estimate perhaps US\$67 million in 2000-and despite some stunning successes in the past two decades, the fundamental problem is not improving. The country must face not only malnutrition but also the political and bureaucratic failure in addressing it. This study defines the nature and extent of the malnutrition problem in Bolivia, identifies the underlying reasons for the failed response, and outlines actions for both immediate and more long-term results.

Malnutrition stunts the body, retards the mind, and consigns its sufferers to the likelihood of poverty and an early death. The most vulnerable are infants-the damage is generally done by the age of two, and full recovery thereafter is virtually impossible. Unless all involved in current nutrition efforts take a new course of immediate, informed, focused action, the incapacities and shortened lifespan that come with malnutrition are the near-certain fate of fully one-fourth of babies now in the womb. But success in the fight against malnutrition in Bolivia-a country that saw remarkable progress in the 1980 s and 1990s-has come to a halt.

The most fundamental barrier to further progress is a general misunderstanding about the causes of malnutrition and its solutions. Largely in consequence, resources are spent on the wrong programs and the wrong segments of the population and the best-designed programs are implemented poorly, apart from the signal success in iodization. This study estimates that less than ten percent of government and nongovernment expenditures with an explicit nutrition or food security component are devoted to effective programs serving the neediest groups-poor pregnant women and malnourished children under two years old. The remainder is spent on lower priority age groups and on less effective programs. The government and donors jointly need to reprogram the bulk of resources toward the age groups and programs that will make the biggest difference to nutrition.

Today, the country is hobbled by the maldistribution of resources, disease, and behaviors that both create and are created by malnutrition. But the potential for success is enormous: Bolivia has the material base and much of the organizational infrastructure to powerfully advance the health and economic well-being of its people: a growing share of the population covered by the basic health insurance program, delivery of basic education, fiscal decentralization, and popular participation in the municipal planning process. These and other resources, properly deployed, along with the country's demonstrated capacity to succeed in the fight against malnutrition, constitute the launch pad for a new phase of well-rounded progress and development. Political will and informed civil society together can provide the fuel for the launch. 


\section{Poverty and Malnutrition are Mutually Reinforcing}

Malnutrition is the handmaiden of poverty. Malnutrition creates poverty by reducing human intellectual and physical potential, and poverty creates malnutrition by restricting economic access to food and increasing nutritional needs and losses. Malnutrition raises child mortality rates, which are now accepted as a priority indicator for measuring the impact of the poverty program.

The PROFILES study (2000) estimates that malnutrition could cost Bolivia more than \$1 billion between 2000 and 2010 in lost human capital and income. Thus, reducing malnutrition will significantly raise Bolivia's potential rate of economic growth. Economic growth by itself will not significantly reduce malnutrition, however. Indeed, while the country's economy has been expanding in the 1990s, rates of malnutrition among the poor have hardly budged. Although solving this problem requires broad, long-term related efforts to improve health, rural development, water quality and sanitation, and education, these programs alone cannot save this generation from malnutrition, nor perhaps the next.

Improving nutrition now is, however, possible with direct, cost-effective, well-targeted nutrition programs that empower families to improve child feeding and that bring vital pharmaceutical supplements and fortified foods where they are most needed. Properly implemented and focused, these direct programs can make an immediate difference in the prospects of children now being born, and for less than is now spent in Bolivia on nutrition programs.

Whether malnutrition is considered in economic terms or in human, moral terms (freedom from hunger is a basic human right guaranteed by the International Convention on Human Rights and the International Convention on the Rights of the Child, to which Bolivia is a signatory), Bolivia cannot afford to ignore the knowledge gained from around the world on how to bring malnutrition under control.

\section{The Context of Malnutrition:}

\section{Poor Diet, Too Much Disease, and Inappropriate Nutrition Behaviors}

Malnutrition and multidimensional poverty are handmaidens, but income poverty is not the cause of malnutrition. Although poor children are more likely to be malnourished than nonpoor children, still, more than half of poorest children in Bolivia are well nourished.

Nor is a lack of food the cause of malnutrition. Most families have enough food to feed their under-two children adequately if they would use appropriate foods that are properly prepared.

If neither income poverty nor a lack of food necessarily causes malnutrition, what does? This study finds most compelling the view, advanced by UNICEF, that finds malnutrition arising from a combination of poor diet, persistent bouts of disease, and inappropriate nutrition behaviors that include insufficient breastfeeding and a breakdown in the infant's eating during and after illness. 


\section{Poor Pregnant Women and Malnourished Children Under Two Are the Highest Priority}

The period of greatest physical growth and brain development for human beings is from conception through about two years of age. Nutritional status during these first 33 months or so of life determines whether an individual can attain full growth, normal health, and mature physical and mental capacity. After children reach the age of two, no amount of nutritional attention can reverse all the damage if they suffered severe and prolonged nutritional deprivation in their first 33 months.

Thus, malnutrition can start in the womb. A malnourished mother who does not eat well during pregnancy and works too hard often gives birth to a low-weight baby (of less than $2.5 \mathrm{~kg}$ ) who is iron-deficient and at high risk of dying.

At birth, all normal newborns should be given only breastmilk (no other food or water) until six months of age lest growth faltering begin shortly after birth. At about six months, the child should start to be given substantial, nutritious, complementary foods and continue to be breastfed until his or her second birthday. Throughout the first two years, special care to maintain eating during periods of illness is critical to the maintenance of growth. Unfortunately, in Bolivian households, especially poor households, the under-two child is precisely the member of the family who is considered to be less nutritionally needy-an extension, almost, of the mother-and the older child or the father is thought to benefit more from the best food that can be obtained. Thus, even if the infant has been breastfed through six months (and only 36 percent of six month old infants were exclusively breastfed in 1998), the complementary foods provided thereafter are often watery, contaminated, and lacking in key nutrients, and breastfeeding is not consistently maintained.

Hence, the child at least from six months to 24 months of age in the poor Bolivian household is usually not fed often enough or encouraged to eat if he or she gets fussy. Because of contaminated food and water, the child usually gets diarrhea, loses appetite, and stops growing. After the diarrhea stops, the child may not be given extra food to recuperate; the growth rate slows, and the child never regains proper height.

The 1998 Demographic and Health Survey shows that the nutritional status of poor, rural, and indigenous children deteriorates most from birth to 24 months of age. By their second birthday, many Bolivian children have become pathologically short and anemic. They cannot fully recover, and because of this they are not likely to do well in school. Such children grow up to be short, physically weak adults with low educational achievement and low earning potential. The female children grow up to be short women who are much more likely to have a small baby and pass malnutrition on to their children. Thus is poverty in Bolivia reproducing itself through malnutrition.

\section{Public and Private Expenditures on Nutrition Are Often Misdirected}

Even though information on public and private expenditures for nutrition is difficult to collect and only approximate, a great deal of money is clearly being spent on programs with nutrition or food consumption goals. An estimated $\$ 67$ million was spent by the 
public sector and nongovernmental organizations (NGOs) on nutrition and food security in 2000. If this money had been delivered as cash to the high-priority population-the 186,000 children under two who are malnourished and the 125,800 pregnant women who are extremely poor-every malnourished child and poor pregnant woman in the country would have received $\$ 216$. This amount would have been more than enough to compensate for any income-related malnutrition (\$216 is 87 percent of the rural extreme poverty line and 67 percent of the urban extreme poverty line). Given that nutrition is not dramatically improving, resources are evidently not reaching those in greatest nutritional need or programs are poorly designed and implemented; in fact, both are true.

\section{Past Successes Should Inspire Action Today}

Bolivia has enjoyed some major successes in the advancement of nutrition over the past . 20 years. Chronic malnutrition fell from 40 percent in 1980 to 24 percent in 1998, and iodine deficiency has virtually disappeared. In the 1990s and into the twenty-first century, however, Bolivia's progress in nutrition has slowed sharply relative to the country's growth in income, and among the poor the progress has stopped. Even today, one-fourth of pregnant women and three-fourths of children under two are anemic. Malnutrition is concentrated among the poor, in rural populations and among indigenous (non-Spanish-speaking) peoples, in households without access to water and sanitation, and where women have low educational attainment.

But best practices from around the world have progressed and are at the disposal of Bolivia if it but resolves to use them-and in the process undoubtedly advance them. For instance, community based growth promotion is now thought superior to clinic based growth monitoring or nutrition surveillance systems (Griffiths, Dickin and Favin) yet Bolivia has not instituted such a program. Communications for behavior change in nutrition which uses client research and trials and the best techniques of marketing has shown significant results (Favin and Griffiths) in many countries but Bolivia still uses didactic materials based on, for instance, the four food groups. School nutrition programs have advanced toward more effective interventions (Del Rosso) but Bolivia persists with school feeding programs, which often don't reach the child until noon. Bolivia has even failed to learn lessons from itself: the Mothercare Project in Bolivia developed innovative ways to motivate pregnant women to take iron supplements (Galloway, et al), yet the lessons learned have not been incorporated into the national health program. Food supplementation programs in Bolivia fail to have exit criteria, incorporate strong nutrition education, and lack firm links to health services in many cases, which have been shown to be effective (though costly) elsewhere in the world (Gillespie).

\section{The Malnutrition Problem Requires Action on Several Fronts}

Certain programs must be created, others need focusing, and the power of administrative decentralization and an energized civil society must drive the political system to make progress against malnutrition. A national vision for nutrition, combined with communication, coordination, and the measurement of nutrition outcomes for program evaluation will tie all efforts together. 


\section{- Nutrition Needs a National Strategy and Functional Leadership}

Nutrition programs in Bolivia suffer from the usual problems of public-sector management-poor planning, cumbersome accounting, weak standards of professionalism in the civil service, and inefficient logistics. But nutrition programs in Bolivia suffer at another level as well. That is, in a number of sectors-health, agriculture, and education, for example-the government has framed an overall strategy that organizes the efforts of the government, donors, and NGOs. Such a strategy is lacking for nutrition, yet so much of the potential success of other programs-indeed, of the society as a whole-is sabotaged for the lack of one. What exists instead are discrete actions in nutrition.

Donors finance 80 percent of nutrition programs, yet among donors there is no consensus on the best approach. For example, one donor may promote food security, another micronutrients, and a third breastfeeding without attempting to maximize synergies, to use the same targeting system, or to agree upon consistent messages and materials in nutrition education. No functional leadership exists to tackle the organizational void that allows such wasteful activity at all levels.

\section{- The Population Needs Accurate and Practical Nutritional Knowledge}

Most of the population does not understand the damage wreaked by malnutrition on learning abilities, disease resistance, and productivity. Nor does it know the size of the problem or the groups most affected by it. Neither the public at large, nor policymakers, nor many nutrition program managers know enough about the causes of malnutrition and how to address the problem. Thus, nutrition does not get the attention it needs and resources are allocated poorly.

Misinformation about nutrition-including the belief that meat and milk are required for a healthy diet-is pervasive, particularly among health personnel. Hence, training and education in nutrition for doctors, nurses, and nutritionists must be overhauled and focused on prevention and counseling.

Nutritional ignorance is particularly problematic at the municipal level, where many programs that affect nutrition-water and sanitation, health, roads, agriculture, employment, social protection, education-are delivered in uncoordinated ways, without communication among agencies, without linkage to macro policies, and sometimes in direct conflict with each other. As a result synergies are not exploited, services either overlap or leave gaps in coverage, and nutrition does not improve. Better knowledge about the importance of nutrition and how to improve is critical to making the most effective use of existing resources.

\section{- Priority Must Be Given to Effective Interventions Delivered to Those in Greatest Need}

Most of the resources in nutrition and food security projects are devoted to food supplements and agriculture infrastructure projects, which are cost-inefficient as nutrition interventions. More money goes to school children and older preschoolers than to the 
higher-priority groups-children under two and poor pregnant women. Nutrition education, arguably the most important intervention, is often of poor quality, based on obsolete concepts and incorrect beliefs about nutrition, and delivered in ineffective waysfor example as group lectures (charlas) with little attention to individual needs, understanding, or resources. If carried out in the manner of international best practice, nutrition counseling, especially for poor families, and the education of the general population would be highly cost-effective and complementary to productive investments in pharmaceutical supplementation, food fortification, and community-based growth monitoring of infants.

\section{- Program Design Needs Improvement}

Local-level planning and sectoral programs are lost opportunities to improve nutrition. Programs in water and sanitation, rural development, roads, education, and credit can have a profound effect on nutrition if they are targeted to the right groups and the synergies exploited. This need not cost any more. The lack of program evaluation at the local level means that no one knows whether any nutritional benefits have been realized.

The lack of participation of poor women in municipal planning means that such planning will not be as effective as possible in addressing the nutrition needs of the poor.

\section{Nutrition is Not Just an Issue for the Ministry of Health}

The Ministry of Health cannot combat malnutrition alone just as other ministries cannot combat poverty alone. The new Phase II Health Reform Loan includes some important new nutrition initiatives, including community-based growth promotion. In other sectors, given the strong link between poverty and malnutrition, nutrition indicators should be used to target and design poverty programs, and nutrition education needs to accompany poverty alleviation. Nutrition can and should be used as a focal point for participatory planning and integrated approaches to poverty reduction. With the necessary technical assistance, municipalities could monitor poverty-reduction activities for their nutritional impact at the municipal level. Nutrition data are inexpensive to collect and they are reliable, sensitive, and timely enough to be used for decision making at the household, community, municipal, and national levels.

\section{An Action Plan for 2003-04}

The Bolivian government, society, and international community could take the following seven concrete actions to improve nutrition within the near term:

\section{Name leaders to develop nutrition vision and strategy.}

One or more credible leaders must be appointed to develop a concrete vision and strategic plan for nutrition. These leaders should be chosen on the basis of commitment to nutrition and management ability, not on the basis of party affiliation. The vision developed in collaboration with the major stakeholders and provide clear guidelines for all levels of government and a clear allocation of responsibility among actors. 


\section{Develop nutrition education focused on the high-priority population.}

The Ministry of Health should develop a coherent national nutrition education strategy, focused on behavior change, with messages developed in collaboration with poor families based on trials of improved practices. The strategy should be focused on the child from birth to two years old and the pregnant and lactating woman and should use social marketing techniques.

\section{Create a private commission to demand continuity of government attention to nutrition.}

The commission should consist of influential members of Bolivian society (including private industry, the Church, academia, foundations, the media, and social action groups). It would review progress in policies, programs, impact, and financing and report to the public. Its primary purpose would be to assure transparency about goals, progress, costs, and benefits.

\section{Improve iron supplementation.}

The Ministry of Health should address the management problems identified in the iron supplementation program.

\section{Invest in municipalities.}

Provide 25 to 30 municipalities with technical assistance in nutrition analysis and actionincluding how to assure the full participation of poor women-to develop a nutrition investment plan for 2003.

\section{Develop community-based nutrition programming.}

PAN and MSPS should develop a model community-based nutrition program focused on growth promotion and derived from the "modalidad indirecta" in the PAN program. The new Health Reform Loan is financing a model community-based nutrition program which could be integrated with the "modalidad indirecta" at the local level.

\section{Make nutrition status an indicator of program success.}

Over the next year the government, with international cooperation, should put in place a monitoring system that includes nutrition status as a key outcome indicator for the PRSP and for interventions in water and sanitation, roads, education, health, and agriculture. Baseline trend data are available from the three ENDSA surveys. 
These actions are all high priority but some high level action and longer time. Some of these are already being implemented. In order to prioritize, some very rough estimates of cost are presented below.

\begin{tabular}{|c|c|c|c|}
\hline Action & Responsibility & Cost & $\begin{array}{l}\text { Currently under } \\
\text { implementation? }\end{array}$ \\
\hline $\begin{array}{l}\text { 1. Name nutrition } \\
\text { leaders }\end{array}$ & Presidency & $\$ 50,000$ per year & No \\
\hline $\begin{array}{l}\text { 2. Develop nutrition } \\
\text { education strategy }\end{array}$ & Minister of Health & $\$ 1$ million & Yes \\
\hline $\begin{array}{l}\text { 3. Create private } \\
\text { watchdog } \\
\text { commission }\end{array}$ & $\begin{array}{l}\text { President and civic } \\
\text { leaders }\end{array}$ & $\begin{array}{l}\$ 10,000 \text { plus } \\
\text { private sector } \\
\text { contributions }\end{array}$ & No \\
\hline $\begin{array}{l}\text { 4. Improve iron } \\
\text { supplementation }\end{array}$ & Minister of Health & $\$ 500,000$ & Yes \\
\hline $\begin{array}{l}\text { 5. Technical } \\
\text { assistance to } 25 \\
\text { municipalities }\end{array}$ & $\begin{array}{l}\text { Minister of Popular } \\
\text { Participation }\end{array}$ & $\$ 250,000$ & No \\
\hline $\begin{array}{l}\text { 6. Develop } \\
\text { community-based } \\
\text { program }\end{array}$ & $\begin{array}{l}\text { Minister of Health } \\
\text { and Director of } \\
\text { PAN }\end{array}$ & $\$ 5$ million & Yes \\
\hline $\begin{array}{l}\text { 7. Measure nutrition } \\
\text { status in ENDSA } \\
\text { and LSMS surveys }\end{array}$ & $\begin{array}{l}\text { Minister of } \\
\text { Finance/UDAPE }\end{array}$ & $\begin{array}{l}\$ 100,000 \text { per } \\
\text { survey }\end{array}$ & No \\
\hline
\end{tabular}

As these actions are taken, improved monitoring and financial management are needed so that Bolivia can track its progress and measure results. 


\section{Introduction}

Malnutrition and poverty are intimately related to each other. At one level, child malnutrition is synonymous with poverty. This is the view that emerges from the argument that poverty is multi-dimensional and manifested in many other forms besides the inadequacy of income or consumption. The lack of access to basic services, illiteracy, and child malnutrition are all manifestations of poverty, according to this viewpoint.

To the poor, of course, well-being and being well fed have always been synonymous. When they are asked to define "well-being," poor Bolivians respond with "food" (youth in Cochabamba), "to be well fed" (middle-aged men in Oruro), "not lacking food" (women in La Paz) or "not to be worried because we know we will have food every day" (women in Tarija). They define the absence of well-being as "bad food" and "to be worried about food."

But malnutrition is also strongly related to income-poverty (that is, the inability of an individual to attain a "minimum" level of consumption). Low incomes constrain the availability of adequate nutrient intake, which in turn causes malnutrition (Behrman and Deolalikar, 1988; Strauss and Thomas, 1995; Deolalikar, 1996). Low incomes are also associated with a higher incidence of diarrheal infections, which reduce the absorption of nutrients from foods that are eaten. On the other hand, income-poverty increases nutritional needs because the income-poor tend to expend a great deal of energy in heavy physical labor; they also tend to be isolated from markets and services (and therefore expend more time and energy to access them) and have a high fertility rate (which places especially high demands on the mother's energy and health). This is shown in Fig. 1.1.

To some extent, malnutrition is also caused by a poverty of knowledge. Many economically-poor Bolivians who are rich in traditional nutrition knowledge (practicing breastfeeding, growing and cooking nutritious Andean crops, using medicinal plants) are nonetheless poor in the knowledge of how to nourish young children optimally with the resources available to them. Moreover, some traditional nutrition "knowledge" involves dangerous practices such as the withdrawal of food from sick children.

The causality between malnutrition and poverty also runs in the other direction. Anemic adults (Levin, 1986), short adults (McGuire and Austin, 1987), and very thin adults (Behrman, 1993 and Thomas and Strauss, 1997), have lower work output in physical labor than better-nourished adults (Strauss, 1986; Deolalikar, 1988; and Thomas and Strauss, 1997). They earn less at piecework jobs, are less productive farmers, and are less likely to be hired for daily wage labor.

Malnutrition also perpetuates poverty. Compared with their better-nourished peers, children who are malnourished during the first two years of life are anemic and are more likely to fail to gain adequate weight and height each month. Their health is worse and their death rates higher (Tomkins and Watson, 1989; Pelletier 1994), they also have a lower probability of enrolling in school and, when they do enter, learn less (Behrman, 
1996; Alderman, and others, 2001; Del Rosso and Marek, 1996). School feeding arrives too late in life to make a difference because much of the damage suffered before the age of two is irreversible (Pollitt, 1996 and Rivera, 1997).

As a malnourished girl matures, she is likely to be short (OPS, 1990), anemic (Gillespie, 1998 and Scholl and Hediger, 1994), and underweight (OPS, 1990). As such she is at higher risk of giving birth to an anemic baby or an underweight baby (less than $2.5 \mathrm{~kg}$ ). In turn, such babies have five times the risk of death in the first year and a high risk of growth failure during childhood. In fact, today, one-fourth of pregnant women in Bolivia are underweight and/or anemic and at risk, through fetal malnutrition, of passing their condition to the next generation. Moreover, low birth weight predisposes the individual to greater chronic disease as an adult, particularly if his health and nutrition environment improves (Barker et al, 2000; McCormick, 1985). Thus, the human and economic potential of one-fourth of the next generation of Bolivians is jeopardized by malnutrition. Bolivia can ill afford to waste one-fourth of its human capital. Reducing malnutrition will reduce human suffering and improve the economic status not just of disadvantaged individuals but of the nation as a whole, and not just of this generation but of generations to come.

Large-scale malnutrition among young children in Bolivia is evidence that economic growth, essential social services, and foreign aid have failed to benefit the poor significantly. The purpose of this study is to examine, in the context of the Bolivian government's poverty strategy, the nature of malnutrition in Bolivia and the public and private actions needed to address the problem. It seeks to widen the space for public debate and to guide action.

Bolivia has in place many of the building blocks of an effective national nutrition strategy-basic health insurance, a participatory local planning process, a comprehensive micronutrient program, and a fundamentally sound macroeconomic policy environment. The fact that Bolivia successfully eliminated iodine deficiency this decade, has doubled exclusive breastfeeding since 1989 , and has instituted a promising iron deficiency control program is a testament to the country's capacity to make progress on nutrition problems that have complex socioeconomic ramifications. Indeed, between 1981 and 1998 the prevalence of chronic malnutrition in Bolivia fell from 40 percent to 24 percent of children under three years of age, and iodine deficiency has been all but eliminated.

Yet, progress is stalling. The reductions in malnutrition were rapid in the $1980 \mathrm{~s}$ and early 1990s; the pace is glacial today. This study finds that many changes, ranging from the fine-tuning of some programs to the major reform of others, must be considered if progress is to be resumed.

Bolivian society today contains the potential for leadership in nutrition. One of the purposes of this study is to draw out and realize that potential by documenting the objective and subjective reality of malnutrition and nutrition programs and providing the space for public dialogue. The development of functional leadership both within and outside the government-leadership, that is, that can articulate a vision, set goals, match plans to resources, monitor progress, and nurture broad participation-is crucial to the 
advancement of nutrition in Bolivia. Our hope is that a sense of urgency and common sense about malnutrition will mobilize civil society to put pressure on the government, NGOs, and the Church to act effectively against malnutrition. The first step in creating demand for better attention to nutrition is sensitization and education of the general public and key stakeholders in nutrition, particularly about the nutritional needs of the poor.

Without functional leadership in Bolivia, both in the government and in civil society, the donors will continue to define the nutrition agenda, in which case discontinuous and inconsistent policies and programs will continue, local ownership will be thwarted, and local capacity for analysis and implementation will be undermined.

Figure 1.1

\section{Relationship Between Nutrition and Poverty}

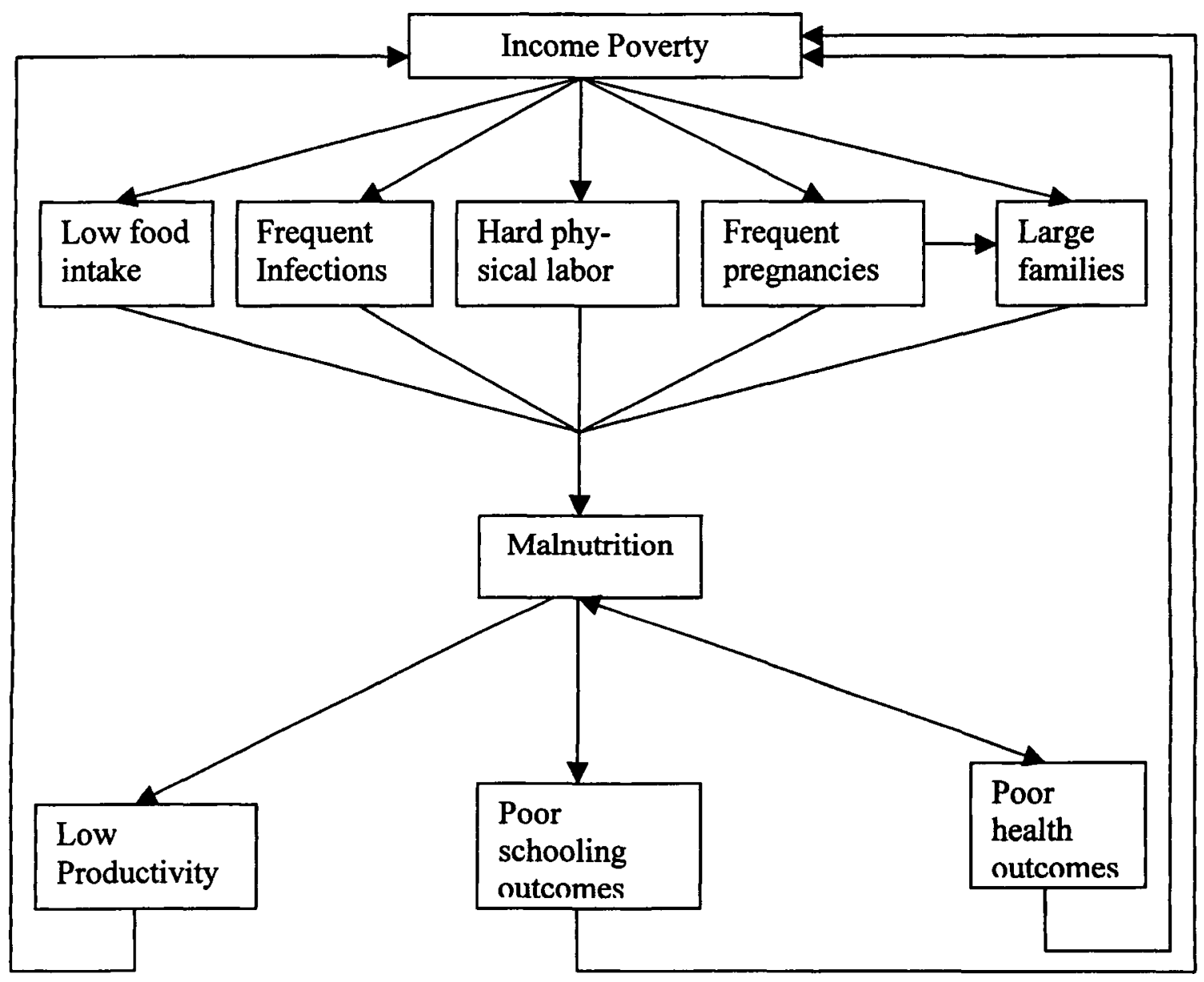





\section{The Nutrition Problem in Bolivia}

Malnutrition, as noted above, may start at birth or before birth. Adequate birth weight is an important endowment for assuring good health and nutrition. Many Bolivian children start life without this endowment.

The period from conception through age two is the time of greatest brain growth and vulnerability for a child. It is the period when good nutrition will have the greatest benefit. Conception through age two is also the period when malnutrition will do the most damage to the brain, to the immune system and to the physical body, and hence to the child's potential for mental and physical development. When inflicted at so vulnerable an age, the damage from malnutrition is generally irreversible; it leads to handicaps in learning, disease resistance, reproduction, and work capacity and causes premature death. For the mother, this is the period of greatest nutritional stress because of the extra demands on her of pregnancy and breastfeeding.

Figure 2.1

\section{Malnutrition is a Cause of Under-Five Mortality in Developing Countries}

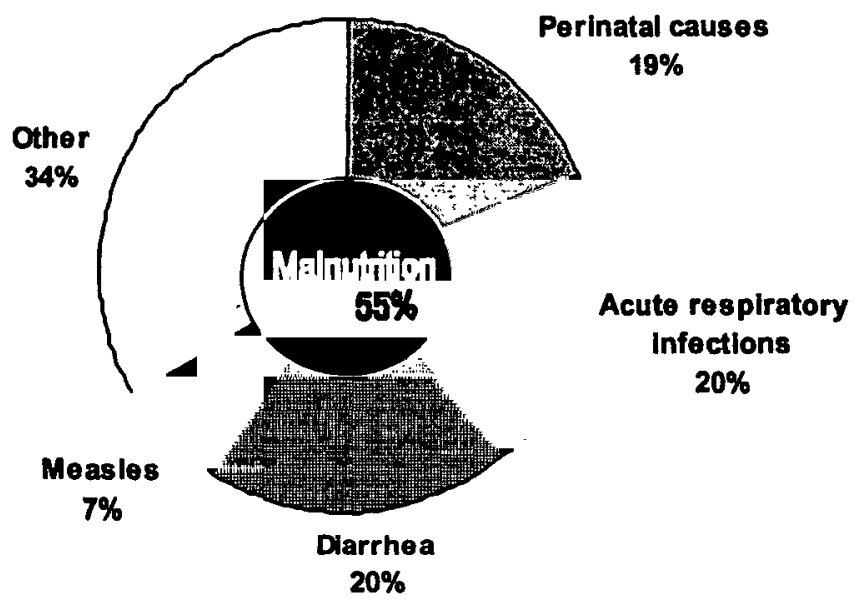

Source: Pelletier, 1994.

Some believe that malnutrition did not exist in prehistoric Bolivia because native foods and equitable governance provided everyone with enough to eat. ${ }^{2}$ In modern times, however, malnutrition has become a major, well-documented health problem. The Demographic and Health Surveys (DHS-ENDSA in Spanish) of 1989, 1994, and 1998,

\footnotetext{
${ }^{2}$ Lavadenz, 2001. Personal communication,.
} 
as well as other surveys, have quantified and mapped the extent of malnutrition in Bolivia. ${ }^{3}$

Likewise, well-established knowledge in nutrition points to the actions that must be the focus of programs if Bolivia is to reduce malnutrition: more effective health interventions among pregnant women and better feeding (including more-prolonged breastfeeding) for the under-two-year-old children among the poor, the rural dwellers, and the indigenous population.

\section{The Prevalence of Malnutrition}

As measured by stunting, about 25 percent of Bolivian children under the age of 3 have suffered malnutrition ${ }^{4}$ - but the rate for the poorest households is about 40 percent, compared with about 6 percent for the wealthiest. Among Bolivian women of child-bearing age, about 12 percent are so short (less than $145 \mathrm{~cm}$ ) that they are at risk of having an underweight baby; and 27 percent of women of child-bearing age are so anemic that they will probably pass iron deficiency to the unborn child.

According to hospital birth records, 12 percent of infants born each year in Bolivia are underweight; the actual rate is surely much higher. ${ }^{5}$ Neonatal mortality has increased between 1994 and 1998 in large part because of an increase in deaths among low-birthweight infants. ${ }^{6}$

${ }^{3}$ INE/MACRO 1989, 1994, 1998; National Institute for Food and Nutrition, 1982; USAID et al. n.d The Social Investment Fund impact evaluation (surveys in 1993 and 1997) includes a socioeconomic survey instrument with an anthropometry module, administered to a large population of participants and nonparticipants in selected poor areas of Bolivia. Unfortunately, nutrition data have not been collected in the same national surveys as household income and expenditure and therefore it is difficult to explore econometrically the relationship between nutrition and poverty on a national level (except through proxy measures available in the ENDSA surveys).

Throughout this study, stunting-low height for age-is used as the main criterion for malnutrition because it is a stable, sensitive, and cumulative indicator. Weight for age ("global malnutrition") is useful for children up to 2 years of age; but after that point it becomes more difficult to distinguish between appropriate low weight for age due to shortness and inappropriately low weight for age due to thinness at a greater height. Low weight for height (thinness) is not used in this study because it is volatile over seasons and periods of sickness and because acute malnutrition results in slowing down the growth process, which ultimately results in a stunted child with normal weight for height.

${ }^{5}$ The weights of only half of new babies-those born in hospitals-are recorded. Babies born in hospitals are both from the wealthier families and at higher risk of complications. The actual prevalence of low birthweight is probably greater than the recorded prevalence. (Gonzalez-Cossio, 1997; NE/MACRO, 1998).

According to ENDSA, 1998, 18 percent of births were considered premature, and 38 percent had no birthweight recorded. According to health cards, only 4.5 percent of children with registered birthweights were of low birthweight. Nonetheless, in the opinion of the mothers, 21 percent of the children were very small or smaller than normal at birth; this opinion, could, however, reflect memory that is biased by the current size of the child.

${ }^{6}$ Lavadenz, 2001 personal communication. 
Micronutrient deficiencies are still a problem. Iron deficiency anemia is widespread in Bolivia. According to the 1998 ENDSA, two-thirds of children under three are anemic largely because of iron deficiency.

Iodine deficiency, which once caused high rates of mental retardation and physical handicaps in Bolivia, has been brought under control through a successful salt iodization program. Vigilance is required, however, to make sure that quality control in the salt industry is adequate to assure sufficient iodine intake throughout the country.

Vitamin A deficiency is potentially a problem, particularly for preschool-aged children, but recent and representative survey data are lacking. Some believe that the monotonous diet consumed in the highlands is lacking in variety and, therefore, in sources of vitamin A.

Because the age at which malnutrition does the most damage is from conception through age two, pregnant women and children under two are the biological groups for whom malnutrition is the greatest risk. Lack of sanitation and inappropriate feeding of children under two are the principal causes of malnutrition in Bolivia. Most of the population of Bolivia lives in cities; yet less than half of all malnourished pregnant women and children under two are poor urban dwellers. The social groups most likely to be malnourished are the rural poor and indigenous populations. Moreover, it is among the rural poor and indigenous populations that progress against malnutrition has come almost to a halt.

\section{Malnutrition Relative to Wealth, Location, and Ethnicity}

Child malnutrition in Bolivia is closely associated with low socioeconomic status, with rural populations, and with indigenous populations.

\section{Socioeconomic Status}

According to the ENDSA survey, a large proportion of the undernourished children under three are in the lower socioeconomic quintiles (42 percent of all stunted children belong to the lowest quintile). ${ }^{7}$ The same survey also finds that the prevalence of under-three malnutrition is greatest among the lower quintiles (40 percent of lowestquintile children were stunted) (figures 2.1 and 2.2). ${ }^{8}$

Looked at another way, the data also show that low income does not always result in malnutrition-indeed, the majority of poor households manage to keep their young children well nourished. Both in 1994 and 1998, nearly 60 percent of the under-3s in the lowest socioeconomic quintile-a group in which total income is too little to buy a

\footnotetext{
${ }^{7}$ Socioeconomic quintiles in the ENDSA were established with a composite score based on housing size and materials, access to cooking fuel, water, sanitation, and electricity, and possession of appliances.

${ }^{8}$ According to the ENDSA survey, about 42 percent of malnourished (stunted) children are found in the lowest quintile of the population, while 3 percent are found in the highest quintile (figure 2.1). Likewise, about 40 percent of children in the lowest quintile are stunted, whereas about 6 percent of them in the highest quintile are stunted (figure 2.2). Carr et al., 2000.
} 
minimally nutritious supply of food-were adequately nourished. Understanding how these poor families produce and sustain well-nourished infants is important for solving the national malnutrition problem.

While low income does not necessarily imply malnutrition, changes in income and changes in malnutrition are inversely related and of similar magnitudes. ${ }^{9}$ On average worldwide, a 1 percent increase in per capita GDP per annum is associated with an annual 1 percentage point decrease in malnutrition without any specific nutrition programs in place (Mason, 1999). And during the 1990s the changes in Bolivia seemed to roughly follow that pattern. In the ten years between 1989 and 1998, stunting decreased 1.4 percentage points per year, from about 38 percent to about 25 percent, as per capita income increased 1.6 percent per year.

The ten-year averages mask, however, a sharp and startling deceleration in the progress against malnutrition in Bolivia and also a reversal in the relationship between income growth and the reduction of malnutrition. That is, from 1989 to 1993, stunting dropped at about the same rate ( 2 percentage points per year) as income rose ( 2.1 percent per year). ${ }^{10}$ But, over the subsequent five years, 1994 to 1998 , as income growth actually accelerated, the annual rate of decline in stunting ( 0.7 percentage points) shrank to less than one-third of the annual rate of increase in per capita income ( 2.4 percent). ${ }^{11}$

Perhaps, the most important finding emerging from a comparison of the 1994 and 1998 ENDSA surveys is that the nutritional benefits of economic growth were distributed very unevenly in the population. During the 4-year period of relatively rapid economic growth, stunting rates among the highest and next-to-highest quintiles dropped by 15.5 percent and 41.2 percent, respectively, while the stunting rate fell by only 4.2 percent in the lowest quintile. This suggests that economic growth is not sufficient in reducing child malnutrition, at least among the poor.

\section{Location and Ethnicity}

In 1998 the rate of stunting among rural children under three years of age and among under-three indigenous children was about the same, around one-third; those rates were almost twice those for urban and non-indigenous children (which were around 18 percent). And between 1989 and 1998, malnourishment declined much faster among the urban and non-indigenous populations (figure 2.3). The relatively favorable urban trends may be the result of the migration of better endowed and therefore better nourished

9 Increases in income at the household level are not always matched by improvements in nutrition probably because of the role of tastes, food variety, and women's time allocation (Behrman and Deolalikar, 1987); Jimenez, 2001).

${ }^{10}$ More generally, nutrition in Bolivia has improved since 1980 at a faster rate than in other Latin American countries. Perhaps as a result, Bolivia has slightly lower rates of malnutrition than would be expected for its GNP relative to other Latin American countries (SCN, 1997).

"GNP from SIMA (World Bank database) in constant 1995 U.S. dollars. 
people from rural to urban areas. ${ }^{12}$ Such migration may also be the cause of a sharp climb in the rate of stunting in Potosi, the poorest department, between 1994 and 1998, and the sharp improvement in the Valles relative to the Altiplano between 1989 and 1998.

\section{The Sources of Malnutrition}

The conceptual framework for this study is that of UNICEF which holds that malnutrition is the product of inadequate food, excessive disease, and caring behaviors.

Figure 2.2

\section{Conceptual Framework}

\section{Proximate Causes of Malnutrition}

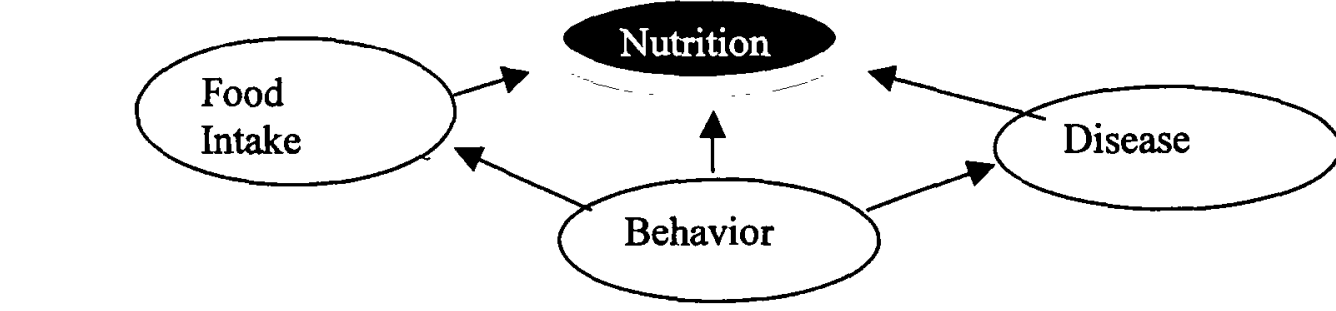

Underlying and Basic Causes of Malnutrition

Household and Gender control over

Human resources

Economic resources

Natural resources
Political structures and ideology

Economic Policies

Access to services

Ecological conditions

Source: INE/MACRO, 1998.

Newborns are protected from nutritional insult until about six months of age if they are exclusively breastfed. Since 1989, the proportion of such babies in Bolivia has risen about 50 percent for the 4-6 month age group and has doubled for all babies under six months, but at less than 40 percent, the overall rate is still far too low. Moreover, feeding practices that create malnutrition for the child older than six months are widespread.

After the age of six months, infants should consume other foods in addition to breastmilk; but among the Bolivian poor, for whom access to clean water and adequate sanitation ranges from tenuous to nonexistent, these older infants often eat unsanitary,

\footnotetext{
${ }^{12}$ The Poverty Diagnostic (World Bank, 2000) notes that migrants are no poorer than others in the receiving areas and less poor than those left behind.
} 
watery soups of poor nutritional quality, drink contaminated water, and crawl on feces-infested surfaces. As soon as inadequate weaning foods and unsafe water are substituted for breastmilk, resistance to disease slips and a downward spiral begins.

Diarrhea, measles, and acute respiratory infections (ARI) become common after six months of age; these diseases cause malnutrition by reducing food intake, increasing nutritional needs, and reducing absorption of nutrients from the food that is eaten. Malnutrition, in turn, reduces immunity, thereby causing diseases to be more frequent, more severe, and more prolonged. When recuperative feeding does not take place after a disease has passed, the child's nutritional status and disease resistance ratchets down. And mothers, especially the poor mothers, typically don't encourage their children to eat during or immediately after an illness, adopting instead a passive attitude to the child's lack of appetite. As the child's growth rate slows, its resistance to disease weakens further, and the vicious cycle continues.

Family food becomes the child's complete diet by about two years of age. Thereafter, the child's nutritional status generally neither worsens nor improves. Thus, by two years of age, the damage is done; the child has become adapted to its environment but at the high cost of serious, permanent damage: immunodeficiency, learning deficits, and reduced physical size and work capacity. Malnourished children also often miss out on social interactions critical to their intellectual, emotional, and social development. And malnourished girls are at higher risk of bearing underweight, anemic babies in the future. ${ }^{13}$

\section{Contaminated Water and Disease}

According to the 1998 ENDSA Survey, about 25 percent of children under three years of age suffered from acute respiratory infections in the two weeks preceding the survey, and about 25 percent suffered from diarrhea (undoubtedly many of these were the same children). In multivariate regression analysis, a child who had had diarrhea in the past month was much more likely to be stunted (Jimenez, 2001). Although more than 20 percent of poor children had contracted diarrhea in the previous two weeks, less than 12 percent of the wealthiest children had been sick.

Water is a critical resource for improving nutrition. In Bolivia, malnutrition is concentrated in areas with low rainfall and low supplies of surface water (Lovon, 2000). Multivariate regression analyses showed that living more than 50 meters from water was associated with more child stunting and that adequate sanitation was associated with better nutrition (INE/MACRO, 1998; Jimenez, 2001).

${ }^{13}$ In the quantitative analysis carried out for this study, multivariate regression analyses were run using height for age as the outcome indicator, with the ENDSA 1998 and the FIS 1993/1997 datasets. In both cases similar causal factors were identified: Better nutrition is associated with females, firstborn children, maternal education, access to water and sanitation, adequate birthweight, and medical attendance at birth (possibly a proxy for access to medical care). Small size at birth (recollected), diarrhea, having a dirt floor, and altitude are associated with malnutrition. 
Furthermore, where water is scarce, women's time and energy must be allocated to procuring water for household use and for stock, presumably at the expense of their own energy, remunerative work, and time for food preparation and childcare. The high variability in rainfall also heightens nutritional vulnerability. Seasonal food shortages, the seasonal incidence of diarrhea, and year-to-year variability in income all contribute to nutritional stress, especially for young children who have little ability to withstand nutritional shocks.

The water problem is not simply one of supply but also of quality. Fecal contamination of the water supply is a source of diarrhea and can be prevented through adequate sanitation and protection of water sources and stored water. Even clean water can be contaminated within the home through unsanitary fecal disposal, domestic animals, and poor hygienic practices. A troublesome finding is that fecal contamination was found in more than half of the water systems installed by the FIS in $1997 .^{14}$

Hence, improvements to the supply and quality of water would be an important aid in reducing the incidence of diarrheal disease, which is a major cause of malnutrition.

\section{High Fertility}

High fertility-too many pregnancies or pregnancies at too early an age, or too closely spaced, or at too late an age-jeopardizes the nutrition of the mother and is also associated with high rates of malnutrition in the children. Only 15 percent of first-born children are stunted, compared with 22-38 percent of higher-parity children. Very short birth intervals are also associated with greater nutritional risk: Less than 20 percent of infants born four years or more after their older siblings are malnourished, compared with more than 30 percent of infants born at a shorter interval. The Poverty Diagnostic found that poverty was worse for households with larger numbers of children (World Bank, 2000).

Fertility causes malnutrition more directly as well. The most common cause of weaning is the arrival of the next pregnancy. Premature weaning can cause emotional and nutritional problems for the infant. The weanling's stomach and taste may not be adequately developed to accept family foods and, as noted above, poor hygiene and the switch to consumption of contaminated water may mean the infant suffers a major assault of pathogens. The MCA also found that women themselves felt they had more children than they could adequately handle, even though the use of contraceptives is low (probably because of lack of availability as well as social censure).

\section{Women's Low Status}

Low or nonexistent educational attainment among women is closely associated with malnutrition. In Bolivia, as shown in the ENDSA report as well as by the quantitative analysis for this study, the amount of education received by women is

${ }^{14}$ The further contamination of water with lead, arsenic, and other chemicals from mines threatens humans directly and also kills fish, a major food source for riparian communities. 
usually highly correlated with their children's nutritional status. About 44 percent of children born to women with no education are malnourished, compared with 34 percent for those born to mothers who have a basic education.

The exact mechanism that connects a mother's education to the nutritional status of her children is unclear, but the content of the education is probably not a factornutrition is largely absent from the curriculum. More likely, education is associated with factors conducive to good parenting. Among these factors are the parental care and attention that are involved when a girl, especially a poor girl, in Bolivia attains some formal education; she can later apply comparable care and attention to her own children (Behrman and Wolfe, 1984). Also, education may confer on women greater autonomy, more earning power, more self-confidence, and less passivity.

Women's control of income has been shown to be positively related to nutritional status of children elsewhere, but such data are lacking for Bolivia (Haddad, and others, 1997).

Clearly men also have an important role to play in childcare, dietary choices, and the allocation of roles and resources within the household. Cultural mores reinforce the traditional division of labor between men and women. The ignoring of men's important role has been common in nutrition programs in Bolivia and has probably contributed to the weakness of the programs. ${ }^{15}$ If men control income and lack the nutrition knowledge, they have no incentive to change their expenditure patterns toward better child nutrition.

\section{The Keystone of a Solution: Proper Feeding of the Under-Two Child}

At bottom, the effort to improve nutrition means changing or influencing a rather sweeping range of behaviors, among them energy expenditure, birth spacing, the developmental attention received by women, child feeding, nutritional management of disease, and the psychosocial stimulation of young children. But the keystone in this arch of behaviors is proper feeding of under-two children.

Proper feeding means feeding infants with only breastmilk until they are six months of age and then continuing to breastfeed them while gradually adding safe, healthy weaning foods until at least the age of two years, with special care to keep the child fed during and after illness. Breastfeeding has unsurpassed nutritional benefits and many non-nutritional benefits as well: It provides the perfect blend of nutrients and hygienic quality for the growing child, represses the fertility of the mother, helps develop the emotional bond between mother and infant, and enhances the infant's cognitive development.

Qualitative studies in both rural and urban Bolivia show, however, that family members tend to see the identity of the child under two years as being undifferentiated

\footnotetext{
${ }^{15}$ Although men's education is an important determinant of household income, it has rarely been shown to have an independent influence on nutrition.
} 
from the mother's. The infant is thus at a great nutritional and hygienic disadvantage relative to the household's adults and older children (UDAPSO/UNICEF, $1996 \mathrm{~A}$ and B; Van Lubek, n.d.). The under-two child, for example, gets fewer meals and must eat from the mother's plate. But probably the biggest problem is the widespread reliance on watery soups for nourishing the infant after six months. These soups simply fill the child's stomach without providing much in the way of calories or nutrients. The mother often does not recognize the resulting emergence of malnutrition until it becomes severe, at which time it becomes a medical problem. These studies also note the lack of self-esteem among women in Bolivia, which limits their ability to learn and to address the challenges of feeding their children and caring for them when they are sick.

\section{Myths of Malnutrition}

Debunking myths about the causes of malnutrition is also important. The dominant misconceptions are that malnourishment stems from: (1) food scarcity and a lack of self-sufficient farming, (2) lack of milk and meat, (3) high altitude, or (4) genetics.

\section{Food Scarcity}

Insecurity of the food supply is often held up as the chief cause of malnutrition in Bolivia (CIESA, 1997). The proof of this insecurity is thought to be Bolivia's status as a net importer of food, which in turn is thought to have caused the disappearance of subsistence farming (CIESA, 1997; PLANSA, 1997; Cariaga and Cariaga, 1996). In reality, fairly recent data (1999) suggest that total food availability is 2,237 calories per person per day, an amount adequate to feed the population if distributed equally (FAOSTAT, Sept. 12, 2001). Of that food supply, about 90 percent derives from domestic production, about 3 percent from food aid, and the remainder from commercial imports. Moreover, official national food supply figures often fail to take into account minor crops, wild foods (hunting, fishing, foraging), contraband imports (particularly from Argentina, which accounted for one-fourth of the flour supply in 1998), and food that is carried into and out of the country by migrants. In sum, the supply of food in Bolivia is adequate if people have the income to buy it.

Food insecurity in Bolivia is largely a matter of income insecurity. If people have money, they can buy food because markets work reasonably well (Comision Europea, 2000). Trade and the commercialization of the food supply are more results than causes of the disappearance of subsistence farming, which has fallen victim to climatic severity and unpredictability, poor soil management and the environmental degradation it produces, and low technology (Centro de Estudios y Proyectos, SRL, 1998 and Government of Bolivia and World Bank, 1998). Hence migration (seasonal or permanent, rural-rural or rural-urban) has become a necessary coping strategy for the rural poor (Prudencio and Cossio, 1998; Davalos. and Dulon, 1999; Paulson and Velarde, 2000). Efforts to advance self-sufficient subsistence farming would be critically 
hobbled by the low carrying capacity of much of the land and the, by now, highly diversified income strategies of rural dwellers. ${ }^{16}$

Several recent studies of rural poverty identified lack of water, roads, employment, markets, and improved technology as being major constraints to improving rural livelihoods and, by extension, food security (Government of Bolivia and World Bank, 1998; Prudencio and Cossio, 1998; Davalos and Dulon, 1999; CARE, 1996; Centro de Estudios \& Proyectos, S.R.L., 1998, Lovon, 2000). The European Commission studies have found that migration income comprises between 3 percent and 40 percent of total incomes of these rural households, and the 1998 study suggests that children are better nourished in households that have more migrants in them (Prudencio and Cossio, 1998; Davalos and Dulon, 1999).

Migration is a double-edged sword for food security, however. On the one hand, temporary migrants send home much needed cash and food. On the other hand, those left at home (usually women and young children) are overwhelmed by farm and household work and often restricted by gender roles in local and household decision-making (Gisbert, and others, 1994).

\section{Lack of Milk and Meat}

Neither milk nor meat is essential for good nutrition (except, of course, breastmilk for the child under two), and both milk and meat have the significant drawbacks of being relatively expensive and highly perishable. Moreover, milk causes indigestion in a large proportion of indigenous people because they are lactose intolerant; it is easily contaminated, especially if it is diluted or made from milk powder; and it threatens iron status by causing microscopic bleeding in the intestines. Compared with a diet with large amounts of milk and meat-out of reach of most of the poor in any case-a diet with vegetable sources of protein, including most basic grains plus beans and Andean legumes, is far cheaper, better suited to local production and household storage conditions, and equally nutritious.

\section{High Altitude}

While it is true that children at greater altitude are more stunted than children at lower altitudes (Jimenez, 2001), it does not follow that altitude causes poor growth. Low birth weight occurs more often at high altitude (Moore, 2001) and is probably due to the lack of oxygen. Low birth weight infants, however, often undergo catch-up growth immediately after birth if they are cared for appropriately (including exclusive breastfeeding). Low birth weight would only explain a small proportion of the total stunting in children under two and it would not explain inadequate weight gain during infancy. Several researchers have noted that at extremely high altitudes (above $4000 \mathrm{~m}$ ),

\footnotetext{
${ }^{16}$ Relatively little land in Bolivia is suitable for cultivation: 5.7 percent is appropriate for agriculture and another $\mathbf{5 2 . 2}$ percent is usable as pasture. Furthermore, the land in use is seriously degraded, and in some parts of the country (particularly the Altiplano), population density apparently exceeds the productive capacity of the land under existing farming methods (Cariaga and Cariaga, 1998).
} 
early childhood growth is slower (Haas, 1982; Greksa, 1986; Obert, 1994) but that environmental factors (health environment and nutrition) far outweigh the altitude effect.

\section{Genetics}

Contrary to popular belief, indigenous children under three are not genetically short. Under proper conditions, these children grow as well as non-indigenous children. It is socioeconomic status and behavior, not genetics, that drive virtually all of their growth pattern (Habicht, 1974; Martorell, 1984).

The next chapter estimates the proportion of nutrition expenditures by the government and NGOs in Bolivia that is devoted to the most efficient programs and the neediest populations.

Figure 2.3

Proportion of Malnourished Children by Quintile, 1998, Bolivia

(expressed as proportion of all stunted children)

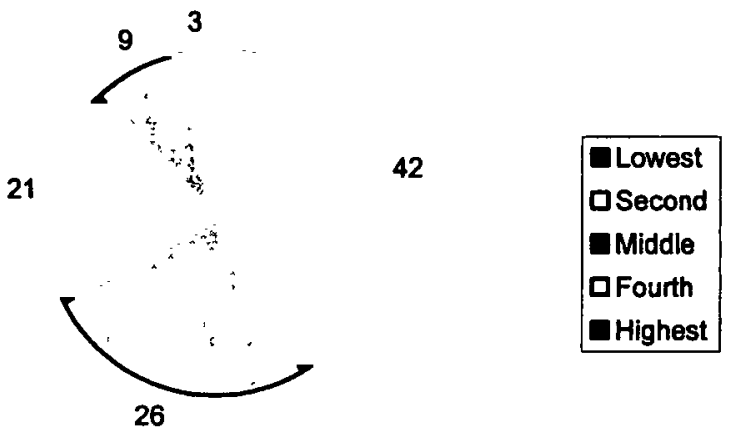

Source: INE/MACRO 1998 
Figure 2.4

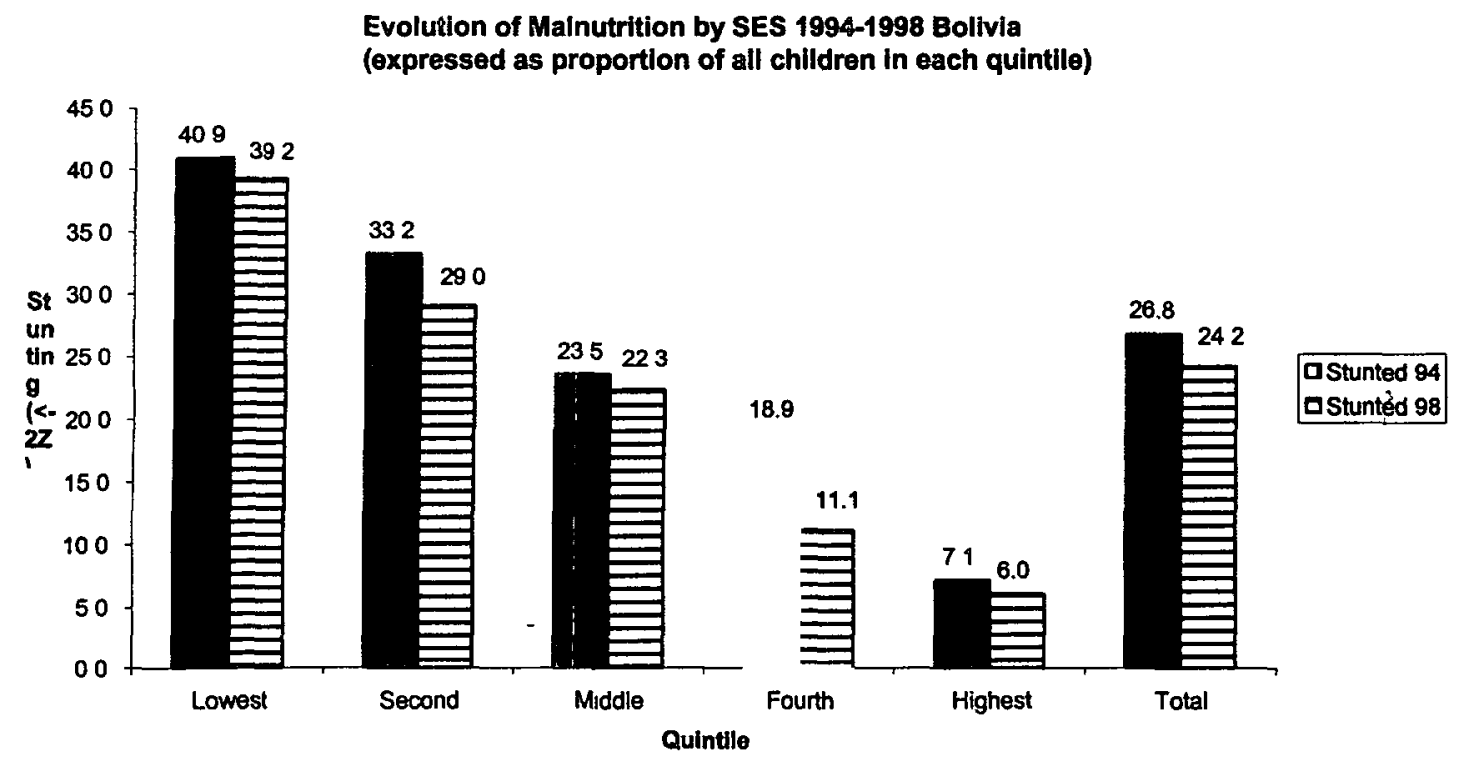

Source: INE/MACRO 1994 and 1998

Figure 2.5

Malnutrition in Bolivian Children Under 3 by Location and Ethnicity

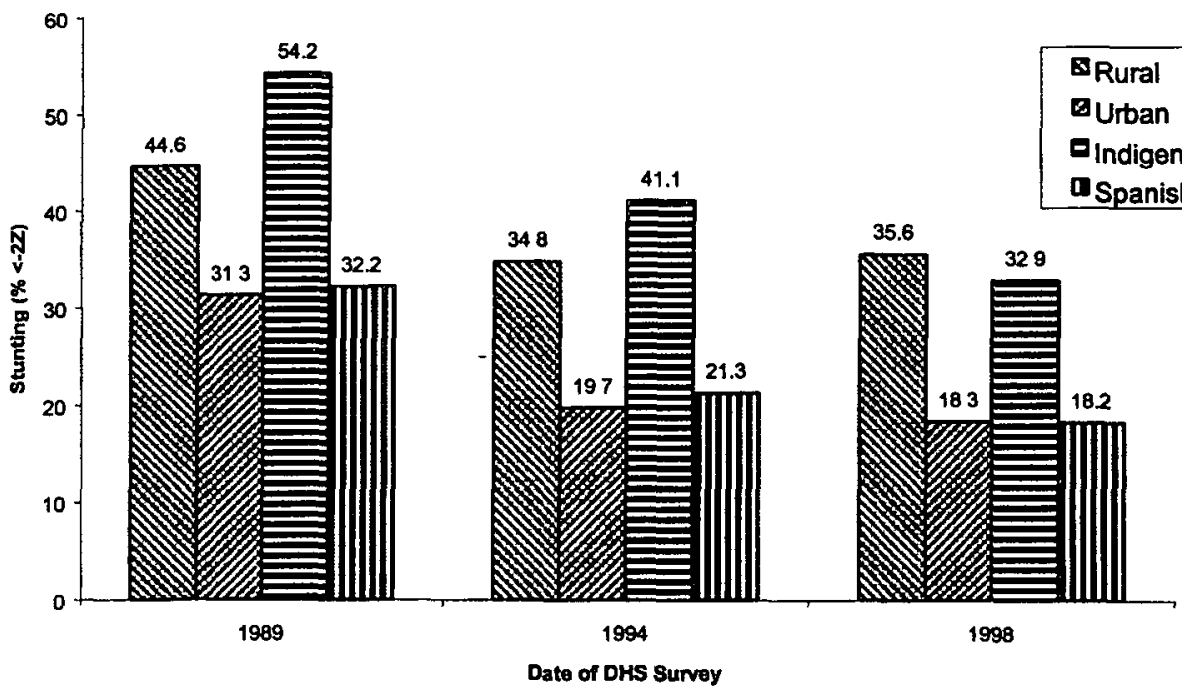

Source: INE/MACRO 1989, 1994, and 1998 


\section{The Targeting and Design of Nutrition Programs in Bolivia}

For the two-year period 1999-2000, this study estimates that approximately US $\$ 1.15$ billion was budgeted in Bolivia for nutrition-related programs: that is, both for direct programs (those specifically focused on nutrition) and for indirect programs (those that could have a strong, if indirect, effect on nutrition).

- Almost all of this amount (about $\$ 1.02$ billion) was for the latter type of programs-overall rural development (\$736 million) and water and sanitation (\$282 million).

- The remaining estimated $\$ 135$ million was budgeted for direct nutrition programs:

- About $\$ 118$ million in the public-sector budget (including donor funds)

- About $\$ 17$ million budgeted by nongovernmental organizations (NGOs). ${ }^{17}$

The programs have the potential to powerfully address conditions underlying much of the incidence of malnutrition-markets and jobs; roads, water, and sanitation; education, health services, and family planning. Unfortunately, the indirect programs do not incorporate nutrition as an objective, nor do they target or design programs for this purpose or track nutritional effects. If this opportunity were seized, substantial improvement in nutrition would be possible without additional expenditure. Their detailed nutritional analysis is therefore precluded.

The nutritional relevance and effectiveness of the direct programs are easier to address, although deficiencies of goal-setting, tracking, and evaluation are serious for them also. The program for action presented later in this study encompasses both the indirect and direct programs and calls for all of them to include nutrition goals and track.

As demonstrated in the preceding chapter, general development and economic growth are not sufficient to improve nutrition, especially among the poor. For all the long-range importance of the indirect programs, however, more and better direct action on nutrition is needed if the problem is to be addressed in this generation. Instructive are two key policy documents on food security and nutrition produced in the 1990s: the 1995 Plan Nacional de Alimentación y Nutrición: Lineamientos Estratégicos del Plan and the 1997 Plan Nacional para la Seguridad Alimentaria ${ }^{18}$. Their strengths and weaknesses are emblematic of the problems with Bolivia's current nutrition programming. Each document proposed an admirable list of programs and initiatives, but

${ }^{17}$ This amount excludes the food and nutrition programs carried out by churches in Bolivia and covers only the 54 NGOs in the PROCOSI (Programa de Coordinación en Salud Integral) and AIPE (Asociación de Instituciones de Promoción y Educación) networks. Other NGOs also have nutrition activities in Bolivia; given, however, that PROCOSI and AIPE are two of the largest network organizations, their spending is likely to represent the bulk of NGO nutrition activity.

${ }^{18}$ The latter was never officially approved, and neither has been implemented. 
neither of them: (1) prioritized among or within sectors, (2) estimated the costs of the proposals they were advancing, or (3) assigned specific institutional accountability for results or (4) specified a monitoring system to evaluate effectiveness. It appears that Bolivia's nutrition activities are not guided by any specific national nutrition policy.

This chapter measures expenditures of the direct programs on the basis of the following criteria:

- Targeting - are programs aimed at the neediest populations?

- Nutritional impact--do the programs achieve their objective of reducing malnutrition among the target groups?

Chapter 6 is devoted to implementation, management, and leadership.

In this analysis, a program was considered a "direct" nutrition program if it included nutrition, hunger-alleviation, or increased food consumption as an objective. Therefore some health programs, the school feeding programs, the PAN (Programa de Atención a Niños y Niñas menores de 6 años) child-development program for children under 6, and food security programs, among others, were counted as direct nutrition programs. As will be shown, however, nutrition programs must be highly focused and employ internationally recognized best practices if they are to alleviate malnutrition among the most vulnerable populations, and many of the programs categorized as "direct" do not make the grade.

\section{Priority Population Targets}

This study identified five "life-cycle" population targets and ordered them into a high-priority group and a lower-priority group on the basis of vulnerability to malnutrition:

High priority

(1) Children under two years of age

(2) Pregnant women (particularly with regard to anemia)

Lower priority

(3) Children ages two to under five

(4) Women of fertile age

(5) School-aged children and other adults.

These populations might be called life-cycle targets as opposed to socioeconomic targets because program targeting based on these priority groups does not address at all the question of whether the poor among them are being reached; precise targeting means reaching the poor people in the correct life-cycle target groups. Sometimes administrative costs and politics preclude precise targeting; nonetheless, the most needy groups should receive the lion's share of the program benefits designed to improve nutrition. 
Most programming directed at children younger than 5 years of age does not specifically address children under two. Therefore, these estimates generally assumed an even distribution of children by age and assigned a proportional share ( 40 percent) of under- 5 program dollars to children under two. These estimations likely overstate the amount actually spent on the under two, however, because except for immunizations, the under two obtain fewer services than do older preschoolers (for example, in the PAN program). None of the programming specifically targeted the poor.

\section{Efficient Nutritional Interventions}

What interventions are most efficient in preventing malnutrition among the high-priority groups? The data necessary to reach such a conclusion are not available from Bolivia because the programs don't track costs nor impacts. In the absence of data on actual coverage, this study followed the second-best option of examining evidence provided by beneficiaries and program managers on targeting. As for efficiency of alternative nutritional interventions, a large number of studies for other countries have documented the types of nutritional interventions that have the largest nutritional impacts for given costs. We have drawn upon this international evidence.

First, measures to promote infant growth, measured as monthly weight gain, can be highly effective in the early identification and correction of faltering growth. Growth promotion is tied in with the promotion of breastfeeding and other good feeding practices for infants and with meaningful nutrition education (Griffiths, and others, 1996).

Second, long-term data from international practice shows that provision of the key micronutrients (iodine, iron, and vitamin A) to under two and pregnant women through pharmaceutical supplementation is very efficient (World Bank, 1994).

Third, food fortification is also highly efficient (World Bank, 1994).

Finally, given the close interactions between ill-health and malnourishment among the under two, health interventions that support healthy infancy, including controlling diarrhea, improving sanitation in the home, and teaching family planning, constitute another complex of important nutrition-related activities. Such interventions typically cost approximately one-half to one-fifth of the cost of food supplements, food subsidies, and school feeding (Table 3.1) and are thought to be effective in reducing malnutrition (McGuire, 1996 and Gwatkin, and others, 1980).

In sum, the most efficient interventions in nutrition are (Table 3.1),

- Growth promotion, the advancement of good infant feeding practices (including breastfeeding), and nutrition education

- Pharmaceutical supplementation of micronutrients

- Fortification of food with micronutrients

- Health interventions linked to nutrition.

The least efficient programs are food supplements, food subsidies, and school feeding. 


\section{Budget Analysis}

Having identified potentially efficient programs and high-priority populations, we can seek to answer the question, How well are programs designed to address the nutrition problem in Bolivia?

Before the numbers are presented, the difficulty encountered in estimating them and the implications of that difficulty bear emphasis. Budget lines for nutritional programs were nonexistent. Clearly, no study before has addressed the issue of public expenditure on nutrition programs and the incidence of this public spending. Without a firm knowledge of the starting point, the development of realistic reform strategies and plans is extremely difficult. The lack of hard scrutiny implies a lack of interest on the part of the government, donors, and NGOs.

Moreover, the program information does not exist that would allow one to say whether the money spent on the high-priority life-cycle groups identified above is spent on the poor in those life-cycle groups.

The analysis covered estimated public expenditures of US\$118 million in the two-year period 1999-2000 (table 3.3) and NGO expenditures of US\$17 million in the same period (table 3.4) (approximately $\$ 135$ million total over the two years, or a bit more than $\$ 67$ million per year). Table 3.1, below, summarizes the results: Only 9 percent of government spending and 7 percent of NGO spending on nutrition was on 'efficient' programs (as discussed in the preceding section) directed at the high-priority groups.

Thus, even without knowing whether the nutrition budget is being spent on the poor, one can say that more than 90 percent of the estimated $\$ 135$ million in public and NGO money budgeted for 1999 and 2000 was spent on the incorrect programs or the not-at-risk populations or both.

Table 3.1 Distribution of expenditures on nutrition, by priority of target group and efficiency (Percent)

\begin{tabular}{|c|c|c|c|}
\hline Priority of target group & Efficient & Not efficient & Total \\
\hline \multicolumn{4}{|l|}{ PUBLIC SECTOR } \\
\hline \multirow{2}{*}{$\begin{array}{l}\text { High priority } \\
\text { Low priority }\end{array}$} & 9 & 1 & 10 \\
\hline & 12 & 78 & 90 \\
\hline Total, public & 21 & 79 & 100 \\
\hline \multicolumn{4}{|l|}{ NGOS } \\
\hline \multirow{2}{*}{$\begin{array}{l}\text { High priority } \\
\text { Low priority }\end{array}$} & 7 & 13 & 20 \\
\hline & 15 & 65 & 80 \\
\hline Total, NGOs & 21 & 78 & 100 \\
\hline
\end{tabular}

Source: Calculations based on data from tables 3.4 and 3.5. See text for definitions of priority groups and efficiency.

3.1. Put another way, if Bolivia's total annual nutrition budget of $\$ 67$ million ( $\$ 58.8$ million from the public sector and $\$ 8.3$ million from the NGOs) were transferred 
only to stunted children under two years of age (186,000 children) and to pregnant women in extreme poverty $(125,800$ women), each person would receive $\$ 216$ annually, which is 87 percent of the rural extreme poverty line and two-thirds of the urban extreme poverty line. ${ }^{19}$ Even if the resources were spent on all children under two, the amount would be $\$ 90$ per child per year. Surely this amount would overcome malnutrition due to inadequate income. In the absence of evidence of any remarkable improvement in the nutrition of poor women and under two, one must conclude that the resources are not reaching those who need them most or that the interventions are far less efficient than a direct transfer of income. Probably both are true and indicate poor implementation and management of the programs, an analysis of which we turn to next.

Table 3.2 Returns on Nutrition Investments (in 1996 US \$)

\begin{tabular}{|c|c|c|c|}
\hline & $\begin{array}{c}\text { Cost per } \\
\text { Life Saved } \\
(\$) \\
\end{array}$ & $\begin{array}{l}\text { Returns to } \\
\text { Program } \\
\text { Dollar } \\
\text { (in wages) }\end{array}$ & $\begin{array}{c}\text { Cost per Discounted } \\
\text { Healthy Life Year } \\
\text { Gained (\$) }\end{array}$ \\
\hline \multicolumn{4}{|l|}{ Undernutrition Interventions } \\
\hline Food Supplements & 18,337 & 1.4 & 234 \\
\hline Nutrition Education & 797 & 32.3 & 10.2 \\
\hline Integrated PHC-N & 9,966 & 2.6 & 127 \\
\hline Food Subsidies & 42,552 & 0.9 & 375 \\
\hline School Feeding & - & 2.8 & 534 \\
\hline \multicolumn{4}{|l|}{ Iron Deficiency } \\
\hline $\begin{array}{l}\text { Supplementation of pregnant } \\
\text { women only }\end{array}$ & 800 & 24.7 & 12.8 \\
\hline Fortification & 2,000 & 84.1 & 4.4 \\
\hline \multicolumn{4}{|l|}{ Iodine Deficiency } \\
\hline $\begin{array}{l}\text { Supplementation } \\
\text { (repro-aged women only) }\end{array}$ & 1,250 & 13.8 & 18.9 \\
\hline $\begin{array}{l}\text { Supplementation } \\
\text { (all people under 60) }\end{array}$ & 4,650 & 6.0 & 37.0 \\
\hline Fortification & 1,000 & 28 & 7.5 \\
\hline $\begin{array}{c}\text { Vitamin A Deficiency } \\
\text { Supplementation } \\
\text { (under five only) } \\
\text { Fortification }\end{array}$ & $\begin{array}{l}130 \\
400\end{array}$ & $\begin{array}{l}50 \\
16\end{array}$ & $\begin{array}{r}4.0 \\
12.3\end{array}$ \\
\hline
\end{tabular}

Source: The Payoff from Improving Nutrition. J. McGuire, World Bank, 1996.

19 Of course, such fine targeting would be extremely difficult in practice and might entail high implementation and administrative costs. In addition, recent research suggests that very fine targeting can undermine political support for an intervention, and result in its derailment (Gelbach and Pritchett 1995, Lanjouw and Ravallion 1998, van de Walle 1998). 


\begin{tabular}{|c|c|c|c|c|}
\hline \multicolumn{5}{|c|}{$\begin{array}{l}\text { Table } 3.3 \\
\begin{array}{c}\text { Expenditure on Nutritional Interventions Targeted to Children Under Two Years of Age } \\
\text { and Pregnant Women, by Program Activity and Financing Agency }\end{array}\end{array}$} \\
\hline Activity & Financing Agency & Amount Invested & Public or NGO & Total in US\$ \\
\hline Growth Promotion & USAID & 4,280 & Public & 5,375 \\
\hline & WB & 140 & & \\
\hline & IDB & 152 & & \\
\hline & Munic.Gov. & 639 & & \\
\hline & PROMUJER/USAID & 30 & NGO & $\overline{216}$ \\
\hline & PROSALUDUSAID & 20 & & \\
\hline & CRS/USAID & 20 & & \\
\hline \multirow[t]{4}{*}{ Lactation } & USAID & 3,979 & Public & 4,087 \\
\hline & UNICEF & 64 & & \\
\hline & $\overline{M G}$ & 6 & & \\
\hline & Linkages/15 NGOs/USAID & 224 & NGO & 270 \\
\hline Nutritional Education & WB & 64 & Public & 216 \\
\hline & IDB & 63 & & \\
\hline & Munic. Gov. - & 26 & & \\
\hline & PROMUJER/USAID & 10 & NGO & $\overline{300}$ \\
\hline & Linkages/15 NGOs/USAID & 224 & & \\
\hline Supplementation & USAID & 102 & Public & 859 \\
\hline & WFP & 370 & & . \\
\hline & Munic. Gov. & 375 & & \\
\hline & APROSAR-SSR-SI/USAID & 20 & NGO & $\overline{118}$ \\
\hline & Plan Int'I-SSR-SI/USAID & 20 & & \\
\hline & PROSALUD-SI/USAID & 18 & & \\
\hline & & & & \\
\hline Fortification & WFP & 319 & Public & $\overline{326}$ \\
\hline Interventions in Health & $\overline{\text { WB }}$ & 10 & Public & 159 \\
\hline Linked to nutrition & USAID & 8 & & \\
\hline & Munic. Gov. & 132 & & \\
\hline & Plan Int'VUSAID & 104 & NGO & 1,204 \\
\hline & Servir/USAID & 112 & & \\
\hline & APROSARJUSAID & 110 & & \\
\hline & PROAGRO/SOH & 70 & & \\
\hline
\end{tabular}

Source: Contributed by government of Bolivia, donors (USAID, UNICEF, WFP), and NGOs

(PROMUJER, PROSALUD, CRS, Linkages, Plan, APROSAR, Servir, Proagro, PROCOSI)PLEASE ADD SOURCE. 
Table 3.4

Summary of Programming for Public Investment for 1999 and 2000 by different level of priority groups (in thousands of US\$)

\begin{tabular}{|c|c|c|c|c|c|}
\hline & \multirow[t]{2}{*}{ Activity } & \multicolumn{4}{|c|}{ Programmed amount } \\
\hline & & Local & Extemal & Total & $\%$ \\
\hline \multirow{7}{*}{$\begin{array}{l}\text { Prevent malnutrition in } \\
\text { children < } 2 \text { years of age }\end{array}$} & Growth Promotion & 743 & 4,632 & 5,375 & $4.57 \%$ \\
\hline & Lactation & 20 & 4,087 & 4,107 & $3.49 \%$ \\
\hline & Nutritional Education & 63 & 153 & 216 & $0.18 \%$ \\
\hline & Supplementation & 375 & 143 & 518 & $0.44 \%$ \\
\hline & Food Assistance & 192 & 667 & 859 & $0.73 \%$ \\
\hline & Interventions in Health linked to nutrition & 34 & 27 & 61 & $0.05 \%$ \\
\hline & - Subtotal & 1,427 & 9,709 & 11,136 & $9.47 \%$ \\
\hline \multirow{6}{*}{$\begin{array}{l}\text { Prevent malnutrition in } \\
\text { children } 2 \text { to }<5 \text { years }\end{array}$} & Growth Promotion & 1,257 & 5,469 & 6,726 & $5.72 \%$ \\
\hline & Nutritional Education & 274 & 532 & 806 & $0.69 \%$ \\
\hline & Supplementation & 562 & 270 & 832 & $0.71 \%$ \\
\hline & Food Assistance & 780 & 3,863 & 4,643 & $3.97 \%$ \\
\hline & Interventions in Healith linked to nutrition & 52 & 28 & 80 & $0.07 \%$ \\
\hline & Subtotal & 2,925 & 10,162 & 12,513 & $11.13 \%$ \\
\hline \multirow{4}{*}{$\begin{array}{l}\text { Prevent anemia in } \\
\text { pregnant women }\end{array}$} & Supplementation & 0 & 341 & 341 & $0.29 \%$ \\
\hline & Fortification & 0 & 326 & 326 & $0.28 \%$ \\
\hline & Interventions in Health linked to nutritlon & 98 & 0 & 98 & $0.08 \%$ \\
\hline & Subtotal & 98 & 667 & 765 & $0.65 \%$ \\
\hline \multirow{2}{*}{$\begin{array}{l}\text { Prevent other illinesses in } \\
\text { women of fertile age }\end{array}$} & Interventions in Health linked to nutrition & 0 & 13 & 13 & $0.01 \%$ \\
\hline & Subtotal & 0 & 13 & 13 & $0.01 \%$ \\
\hline \multirow{2}{*}{$\begin{array}{l}\text { Prevent other micro- } \\
\text { nutrient deficiencles }\end{array}$} & Supplementation & 0 & 18 & 18 & $0.02 \%$ \\
\hline & $\begin{array}{l}\text { Subtotal } \\
\end{array}$ & 0 & 18 & 18 & $0.02 \%$ \\
\hline \multirow{6}{*}{$\begin{array}{l}\text { Prevent malnutrition in } \\
\text { less priority populations }\end{array}$} & Growth Promotion & 261 & 481 & 742 & $0.63 \%$ \\
\hline & Nutritional Education & 108 & 5,625 & 5,733 & $4.87 \%$ \\
\hline & Fortification & 0 & 448 & 448 & $0.38 \%$ \\
\hline & Food Assistance & 20,559 & 9,117 & 29,676 & $25.23 \%$ \\
\hline & Food Security & 119 & 55,881 & 56,000 & $47.61 \%$ \\
\hline & Subtotal & 21,047 & 71,552 & 92,599 & $78.73 \%$ \\
\hline Total & - & 25,497 & 92,121 & 117,618 & \\
\hline
\end{tabular}

Source: Contributed by government of Bolivia, donors (USAID, UNICEF, WFP), and NGOs (PROMUJER, PROSALUD, CRS, Linkages, Plan, APROSAR, Servir, Proagro, PROCOSI)PLEASE ADD SOURCE. 
Table 3.5

Summary of Programming for NGO Investment for 1999 and 2000 by Different Level of Priority Groups (in thousands of US\$)

\begin{tabular}{|c|c|c|c|}
\hline & \multirow{2}{*}{ Activity } & \multicolumn{2}{|c|}{ Programmed Amount } \\
\hline & & Total & $\%$ \\
\hline \multirow{7}{*}{$\begin{array}{l}\text { Prevent malnutrition In children }<2 \text { years of } \\
\text { age }\end{array}$} & Growth Promotion & 216 & $1.30 \%$ \\
\hline & Lactation & 270 & $1.63 \%$ \\
\hline & Nutritional Education & 300 & $1.81 \%$ \\
\hline & Food Assistance & 1,818 & $10.95 \%$ \\
\hline & Food Security & 63 & $0.38 \%$ \\
\hline & $\begin{array}{l}\text { Interventions in Health linked to } \\
\text { nutrition }\end{array}$ & 150 & $0.90 \%$ \\
\hline & Subtotal & 2,817 & $16.97 \%$ \\
\hline \multirow[t]{6}{*}{ Prevent malnutrition in children 2 to $<5$ years } & Growth Promotion & 390 & $2.35 \%$ \\
\hline & Nutritional Education & 106 & $0.64 \%$ \\
\hline & Food Assistance & 4,240 & $25.54 \%$ \\
\hline & Food Security & 87 & $0.52 \%$ \\
\hline & $\begin{array}{l}\text { Interventions in Health linked to } \\
\text { nutrition }\end{array}$ & 294 & $1.77 \%$ \\
\hline & Subtotal & 5,117 & $30.82 \%$ \\
\hline \multirow[t]{4}{*}{ Prevent anemia in pregnant women } & Supplementation & 118 & $0.71 \%$ \\
\hline & Food Security & 272 & $1.64 \%$ \\
\hline & $\begin{array}{l}\text { Interventions in Health linked to } \\
\text { nutriton }\end{array}$ & 50 & $0.30 \%$ \\
\hline & Subtotal & 440 & $2.65 \%$ \\
\hline \multirow[t]{2}{*}{ Prevent other illnesses in women of fertile age } & $\begin{array}{l}\text { Interventions in Health linked to } \\
\text { nutrition }\end{array}$ & 1,004 & $6.05 \%$ \\
\hline & \begin{tabular}{|c|} 
Subtotal \\
\end{tabular} & 1,004 & $6.05 \%$ \\
\hline \multirow[t]{2}{*}{ Prevent other micro-nutrient deficlencies } & Supplementation & 300 & $1.81 \%$ \\
\hline & $\begin{array}{r}\text { Subtotal } \\
\end{array}$ & 300 & $1.81 \%$ \\
\hline \multirow{5}{*}{$\begin{array}{l}\text { Prevent malnutrition in less priority } \\
\text { populations }\end{array}$} & Growth Promotion & 98 & $0.59 \%$ \\
\hline & Nutritional Education & 192 & $1.16 \%$ \\
\hline & Food Security & ${ }^{20} 6,490$ & $39.09 \%$ \\
\hline & $\begin{array}{l}\text { Interventions in Health linked to } \\
\text { nutrition }\end{array}$ & 146 & $0.88 \%$ \\
\hline & Subtotal & 6,926 & $41.71 \%$ \\
\hline Total & & 16,604 & \\
\hline
\end{tabular}

Source: Contributed by government of Bolivia, donors (USAD, UNICEF, WFP), and NGOs (PROMUJER, PROSALUD, CRS, Linkages, Plan, APROSAR, Servir, Proagro, PROCOSI)PLEASE ADD SOURCE.

20 This amount reflects activities related to production only, not to micro-credit or water and sanitation programs as in the case of public investment so as to have comparable numbers. 


\section{The Implementation and Management of Nutrition Programs in Bolivia}

Several nutrition and nutrition-related programs in Bolivia are well-designed: salt and flour fortification, breastfeeding promotion, and PAN. Most of the nutrition programs examined by this study, however, are poorly implemented; they fall short of international good practice and need to be overhauled to meet current standards. On the surface, their deficiencies stem from management problems. De facto responsibility is divided among ministries, and no individual or entity is held accountable for nutrition. Managers and policymakers do little or no communicating or coordinating among themselves and pay little or no attention to tracking the effects of their programs. The result is poor targeting, overlaps and gaps in coverage, loss of synergies among interventions (water and health, for instance), inefficient competition among programs for participants and resources, and inconsistent or even conflicting nutrition messages.

New organizations have been created to "coordinate" food and nutrition programs, but they have not succeeded. The institutional analysis conducted by this study indicates that the underlying causes of the management problems in nutrition programs are the lack of a clear and shared vision for nutrition, the lack of leadership, and, finally, the lack of political commitment. ${ }^{21}$

Donors deserve part of the blame for this frenetic activity. As noted in the previous chapter, 80 percent of the nutrition financing is external. Donors have financed projects of interest to them rather than capacity building in the government or long term investment programs in nutrition. Most aid comes preprogrammed and much of it comes in the form of food commodities, not all of which can be monetized. Because of the institutional weaknesses in national institutions, these prefabricated projects cause programmatic whiplash as donor themes change.

\section{Program Implementation}

International experience shows that prevention of malnutrition in children is far more effective in reducing malnutrition and less costly than treating it. The world's most effective malnutrition prevention programs, at least in rural areas, are not facility-based but community-based-that is, they bring service to the community or even the household rather than require families to come to the clinic or center outside their community (Griffiths, and others, 1996). The new Integrated Management of Childhood Illness (IMCI) program and basic nutrition packages (Sanghvi and Murray, 1997) are better incorporating nutrition into health services, and IMCI is helping legitimize nutrition in the medical community. Nonetheless, all nutrition programs in Bolivia should be more

\footnotetext{
${ }^{21}$ Vision in this case is defined concretely in terms of clearly delineated clients (internal and external), services, and standards for those services, at present and at a fixed point in the future. The fact that the Consultative Group could not find any quantitative nutrition goals for the country or data to determine how well they are doing is evidence of lack of a concrete vision.
} 
focused on prevention and promotion at the family and community level. The Community IMCI program (which is still in the development phase) has also focused almost exclusively on detection and treatment of disease; prevention is clearly a second-thought.

The need to bring nutrition programs into the community and into homes raises the issue of Bolivia's political decentralization program. Bolivia boldly embraced decentralization in the early 1990s, leaving decision making about many development programs to municipal planners, many of whom were not prepared for the challenge. Since then, basic financial management skills at the local level have been improved. But better local planning and management is needed to make sure that effective programs that address high-priority needs are financed and that related programs are coordinated. And much remains to be done to include the poor in planning and decision making. Technical capacity at the municipal level is extremely low in nutrition. Expertise does exist at the departmental level in both health and PAN but these skilled individuals are not deployed to work on municipal nutrition planning (and program management skills are limited).

Participation by the poor, particularly indigenous people and women, is not strong in most municipalities. A lack of trust in the municipal processes was common among respondents to the MCA. In some of the fifteen municipalities studied for the constraints assessment, the economy is controlled by a small number of landholders who essentially hold the poor captive. In others it is the teachers or other professionals from outside who hold the most power. The MCA frequently recorded complaints about the lack of respect shown to the poor by public servants. Many of the women respondents had no knowledge of development programs operating in the municipality in which they lived. To make participatory municipal planning work, the poor need to be given respect, information, and voice in the decisionmaking.

The more urbanized ("in town") households tend to capture most of the benefits from the municipal government. In Villa Rivero (Cochabamba) for instance, 60 percent of the municipal budget was spent on projects in town where only 20 percent of the population lived. In the northern areas of Potosi, the UNDP study found that the poor were moving toward "nuclearización" (coming together of households) to capture more benefits from social projects. Mayors tend to opt for projects with tangible benefits to demonstrate to the population that the mayor is watching out for his constituents. These tendencies, coupled with the lack of understanding of nutrition, have meant that little good nutrition work has been done at the municipal level with locally programmed money. Food programs seem to have been divisive, causing jealousy and corruption; and they have focused attention on food (which is, after all, a wage good) at the expense of nutrition.

If the government takes nutrition seriously, it will have to help improve the ability of the municipalities to analyze nutrition problems and develop appropriate programs. The Ministry of Popular Participation must take a more active role in providing technical and financial assistance to municipalities in nutrition. The Participatory Rural Development Project, financed by the World Bank, has shown that technical assistance to municipalities can result in greatly improved participation and in better municipal 
planning (ICR, 2001). Under the nutrition elements of such a program, support to municipalities could focus on the most efficient strategies: community-based growth promotion, infant feeding and other nutrition education programs, pharmaceutical supplementation, and food fortification.

\section{Growth Promotion}

Over the past decade, the operational approach to nutrition worldwide for young children has undergone a paradigm shift in two dimensions-age and nutrition indicator. The age group of greatest concern has shifted from children under five to those under two or even under 18 months; the indicator for nutrition has shifted from nutritional status (such as some cutoff of weight for age) to growth, measured as monthly weight gain. ${ }^{22}$ The shift is significant in operational terms because a static criterion such as weight for age is defined in a broad range, and too much time can go by before an infant falls below the acceptable range. Monitoring monthly growth, however, offers the possibility of catching and correcting a negative nutritional trend earlier and hence more effectively. Growth promotion has been successfully implemented in Sri Lanka, Indonesia, Tanzania, and Honduras (Ranatunga, 2000; UNICEF 1989 and 1993; Anon, 2000; Zeitlin, and others, 1984; and Ho, 1985).

Embracing the shift to growth promotion requires, however, that health agents and young children have monthly interactions and that the agents take a behavior-change approach to nutrition intervention. It requires intervention as soon as a faltering in growth begins and before a child becomes malnourished. A shift to growth promotion implies, therefore, a range of additional efforts that include dynamic, effective nutrition education and the promotion of good infant feeding practices, including breastfeeding. It generally requires a community-based program. But in Bolivian, growth monitoring takes place only when the child appears at a health center, generally because of illness. Because the sick-child visits are not regular, nutritional status (whether the child falls above or below specific lines on the growth chart), not growth rate, is measured, and the results are not used for decision making or counseling. If anything, children are weighed primarily to provide data to the information system, which itself is not analyzed or used for decision making (Daza, 2000; Paulson and Velarde, 2001).

For example, PAN participants are regularly weighed at health clinics, and their growth charts are maintained at the PAN centers, but the weight gain is not used for decision making or counseling of parents. Few, if any, of the staff members reviewing the data know how to interpret the growth curve and, if inadequate weight gain is detected, how to act on it. Instead, a static measure of nutritional status is used, regardless of growth performance, to identify children for special feeding. ${ }^{23}$ A recent

\footnotetext{
${ }^{22}$ Although this study uses stunting-low height for age-as the most reliable statistical criterion for malnutrition across all age groups, weight for age-as noted in chapter 2-is still an appropriate measure for children up to 2 years of age. Weight gain is used in programs, not in national surveys.

${ }^{23}$ Moreover, the criterion used to define malnutrition is set too high, at -1 standard deviation below the international mean, so malnutrition is needlessly over diagnosed, causing attention to be diverted from the neediest children.
} 
informal review of these growth charts showed inadequate weight gain, over an extended period, for a large proportion of participants that was not detected or addressed.

In Bolivia, growth promotion is done at the community level by only a small number of NGOs as part of larger community development projects (Sullivan, and others, 1999). Community-based nutrition programs measure and use the growth of children as a diagnostic and decision-making tool for the family and the community. The household's decisions most relevant to nutrition determine breastfeeding practices and, within the resource constraints faced by the family, the number of meals given per day and the density and quantity of food at any meal. Beyond the household, community mobilization to improve child growth and development can lead to community-led interventions in water and sanitation, childcare, food production, and women's income generation projects, and it can lead to greater participation by men in resolving nutrition problems (Ranatunga, 2000; UNICEF, 1993). The link between community-based growth promotion and popular participation processes is obvious but needs to be made.

\section{Promotion of Infant Feeding and Other Nutrition Education}

The field of nutrition education has also undergone a revolution in the past twenty years. The concept of didactic, one-size-fits-all messages (in Bolivia, the nutrition charla) is obsolete as is nutrition education designed in the capital city on the basis of abstract principles, like the basic four food groups, and good artwork.

Best practice in nutrition education (including breastfeeding promotion) now focuses on tailoring messages to the intended audience through the right medium and with the right frequency. Effective communications use social marketing principles to make sure the product being promoted (new behavior), message placement, "price" (both monetary and psychological), and promotion are right (Favin and Griffiths, 1999).

To apply these principles communications strategies should be based on in-depth research with target groups concerning major resistance points and motivational factors and be validated through trials of improved practices (TIPS) with intended beneficiaries. On-the-ground research is required (Griffiths, and others, 1996; Dickin, 1997). Bolivia has some of the basic building blocks for excellent nutrition education but neither the program framework nor the commitment and talent available has been brought to bear to implement an effective nutrition education strategy.

Common sense in current nutrition education messages is notably lacking. Although families value the concept of nutrition education, study respondents said that the nutrition education sessions they attend-all group lectures-were boring, irrelevant, and condescending (Paulson and Velarde, 2001). Their comments also indicated that the messages are inappropriate to the nutrition problem and to the economic means of the clients. The widespread message that meat and other high cost foods are necessary for good nutrition is not only wrong, it is completely unrealistic for poor families. Messages often include the converse as well: that potatoes, noodles, bread and other starchy foods (which constitute the bulk of the diet of the poor) are bad for nutrition. 
Added into this nutritional Tower of Babel are a welter of (unregulated) nutrition messages promoting sardines, soybeans, vegetarianism, weaning foods made of garbage, and commercial milks and infant formulas. No wonder people are confused. At the same time that new foods are being promoted, nutritious traditional foods that are well adapted to the growing conditions (quinoa, tarhui, amaranth) are being forsaken.

The problem with nutrition education in Bolivia rests not only in the messages but also in the medium. The medium in most cases is presumed to be a doctor, nurse, or nurse auxiliary. These personnel have received scant training in nutrition or nutrition education and they lack supporting materials. Moreover, nutrition education is not built into their job descriptions and thus they have little time, inclination, or guidance on how to do counseling. Finally, health staff are located within fixed facilities rather than in the community. They are simply too distant from the people who need them-physically and culturally-to be effective in changing daily behaviors like feeding. Hence, nutrition education either isn't done at all or it is done poorly.

Some excellent research has been done in Bolivia on nutrition behaviors of typical target groups, but the findings have not yet made their way into nutrition education strategies or materials (UDAPSO/UNICEF, 1996; van Lubek, n.d.). The acronym FADU, developed in Bolivia as part of this research, is an excellent mnemonic for remembering the key problems of infant feeding: frequency, adequate amount, density (thick consistency), and use (active feeding). Unfortunately, the work necessary to incorporate FADU into appropriate counseling materials and a communications strategy remains to be done.

Another example of unrealized education potential concerns iron supplementation. Between 1996 and 1999 the Mothercare project on iron supplementation of pregnant women, financed by USAID, developed excellent counseling materials, posters, take home reminders, training materials, and tablet containers to respond to issues identified in formative research (OMNI, 1997; Galloway, and others, 2002). These materials increased compliance with the iron supplementation program and hence its effectiveness. Unfortunately, for unknown reasons, the materials have not been employed by the Ministry of Health. It was found that iron supplementation is not a high priority among its doctors, nurses, and decision makers (Lopez, 2000).

\section{Micronutrients}

Pharmaceutical supplementation of iron is a critically important nutrition intervention that is not being implemented effectively in Bolivia. Vitamin A supplementation is suffering from the lack of an education component, and vitamin $A$ fortification is bogged down in disagreements, industry opposition, and political apathy. On the other hand, iodine fortification is a great success.

\section{Iron}

Many of the building blocks of an effective iron-deficiency control program are in place in Bolivia: Iron fortification of flour is being implemented, iron supplementation 
programs have been formally approved for pregnant women and children under two, and effective nutrition counseling materials exist (for pregnant women). Furthermore, donors have provided strong support, at least for the pharmaceuticals. Yet these steps are not enough. Iron programs should explicitly target children under two and pregnant women and should make iron supplements available at the community level; these program features have not yet been made policy in Bolivia.

The iron supplementation program has some minor technical problems (the dose of iron for children is too low and materials to aid the counseling of young children are not available). In addition, iron supplementation has a major implementation problem: The program is not being executed adequately. As shown in the MnCA, problems stem from lack of unambiguous accountability for the program, logistics failures (failure to get enough supplements in good condition to the right place at the right time), lack of internal communication (norms are not disseminated, for instance), and uncommitted, unmotivated personnel (Lopez, 2000).

The evaluation of the iron program by the World Food Program (Daza and Alvarez, 1999) found that:

- About two-thirds of pregnant women never received any iron tablets even though most of them ( 88 percent) were covered by prenatal care.

- The supply of iron tablets is only 29 percent of actual requirements.

- No one received the requisite 90 tablets in prenatal care.

Through better tablet packaging, logistics and counseling, the Mothercare program was able to increase tablet consumption by pregnant women in prenatal care: the proportion of such women taking at least 30 tablets increased from 26 percent to 62 percent, and the proportion taking at least the requisite 90 tablets, increased from 6 percent to more than 19 percent (Galloway, and others, 2002).

One of the most efficient responses to iron deficiency anemia in the general population is food fortification. Fortification is regulated and enforced by the government but carried out by private industry. Under best practices (World Bank, 1994),

- The cost of the fortified food is affordable

- The fortified food is acceptable to the consumer

- Standards and the allocation of responsibility for quality control and enforcement is unambiguous

- Enforcement is transparent and honest

- Widespread public education promotes the program

- A good population-based monitoring system supports the program.

Fortification is an addition to, not a replacement for, iron supplementation for pregnant women and children under two. Industry appears to be doing its part in the fortification program, but the government has not fulfilled its commitment to launch a public education campaign. The success of flour fortification depends critically on 
stopping the contraband import of unfortified flour from Argentina. The new administration of the Customs Services appears to have made a difference in the illegal imports (Weinstein, 1999). Overall, however, the public sector still lacks the infrastructure and the management clarity to monitor industry and customs compliance with the regulations (Daza and Alvarez, 1999).

Another characteristic of successful iron programs is treating hookworm where it is found. Hookworms attach themselves to the intestinal wall and suck blood from the host. High hookworm loads cause anemia. Annual or semiannual deworming of school children, which breaks the transmission cycle of the parasite within the community, tends to be the most efficient approach . Wearing footwear, hygiene education, and improving sanitation are also critical to eliminating hookworm as a public health problem. Bolivia does not appear to have a proactive hookworm control program in place.

\section{Iodine and Vitamin A}

The salt iodization program has been very successful. Over 90 percent of salt consumed in Bolivia is now iodized. All that is required is continued vigilance both on populations at high risk (e.g., isolated high-altitude villages) and on industry compliance. Special measures to get iodine to isolated populations may be needed. As with iron-fortified flour, clear standards, honest enforcement, and permanent population monitoring are critical to long term success. Salt iodization is a tremendous achievement of which Bolivia is justifiably proud.

Vitamin A distribution through mass immunization days appears to achieve high coverage, although there are significant problems with stock-outs, expired capsules, lack of appropriate dosage capsules, and disintegration of capsules (MnCA). Vitamin A appears to be well accepted by medical personnel. The lack of progress on vitamin A fortification of a commercially available foodstuff is the result of lack of high-level political commitment in the face of resistance by the sugar industry and, apparently, disagreements among nutritionists about the best vehicle. Vitamin A fortification of oil distributed to sick children through the health system appears to have serious logistical and training problems that make the oil largely unavailable and in any event is not designed to prevent vitamin A deficiency.

The vitamin A supplementation program follows widely accepted best practices, but it is not complemented with an effective nutrition education program. Communications for behavior change, combined with agricultural extension to promote production and consumption of foods rich in vitamin $\mathrm{A}$, has been successfully used elsewhere; it is not being carried out in Bolivia.

\section{Water Programs and School Feeding}

This study also looked in some detail at other activities relevant to nutrition, especially water resource programs and school feeding. In different ways, improvements in these programs could have important repercussions for direct efforts in nutrition. Better management of water resource programs could deliver the safe water and sanitation that is fundamental to the health and nutrition of families and is especially 
lacking in rural areas. School feeding programs, which are widely misunderstood in Bolivia as being a weapon in the fight against malnutrition, nonetheless have a role to play in health and education, and they are a felt need among the poor; greater efficiency in their operation and better understanding of their purpose could free significant resources for nutrition programs targeted to the priority populations-the under two and pregnant women of poor families.

\section{Water}

Less than 30 percent of rural households have a connection for water in their homes or yards, compared with almost 90 percent of urban households, and such connections are among the highest-priority demands of the poor. The availability of sanitation is even more unequal. Given the crucial relationship of water and sanitation to health and nutrition (as discussed in chapter 4), indicators of malnutrition should be included in the targeting criteria for water projects, and municipalities should be given incentives to invest in areas of highest health and nutrition risk.

When integrated with public health measures, water programs in Bolivia have indeed reduced malnutrition (and, importantly, reduced women's workload by two hours per day) (Lovon, 2000). Factors that are likely to increase the positive impact of water and sanitation programs are the presence of a maintenance person in the community along with adequate technical backup, the inclusion of women on the water committee, and integration of domestic water, productive (for example, irrigation) water, and sanitation in the same package (Sara, and others, 1996). The sustainable livelihoods approach appears to address many of the forward and backward linkages that maximize the effectiveness of water interventions as a means of improving nutrition.

\section{School Feeding}

Chronic malnutrition is correctable only in the first two years of life; hence, school feeding must be seen as at best an education intervention, not a nutrition intervention. Even then, experience from around the world suggests that school feeding is very expensive and should be undertaken only where no other, more efficient solutions are available for attracting children to school. As implemented in many communities in Bolivia, however, the school feeding program is not likely to be helping school performance-the meal is often delivered closer to lunch than to breakfast, and thus the child in need will have spent half the day with hunger pangs; and it may even be making some children worse off in terms of overall food intake-their parents, who often get no counseling as part of the program, may actually withdraw food at home because they think that the children are getting all they need to eat at school. On the other hand, the school breakfast program is delivered in many communities where the children are not generally suffering from a lack of food (Meresman, 1999; Sullivan, and others, 1999).

An evaluation by the World Food Program found that anemia (found in three-fourths of third-graders and half of sixth-graders) had a greater effect on educational outcomes than did chronic undernutrition (Zamora and Barrera, 1998). Yet iron fortification and supplementation and (where appropriate) deworming are not 
generally part of the school feeding program. Nor are parent education, basic school health services, or the teaching of sound nutrition practices in the school curriculum.

If targeted to the communities that need it most, the school feeding program in fact provides an enormous opportunity to change a fundamental aspect of thinking among poorer families, namely that the children most in need are school-aged. Proper counseling for the parents and education for the children as part of the breakfast program could focus on the needs of the under-two child, for whom chronic malnutrition will permanently reduce the capacity for achievement in school. Done properly, the school feeding program could thus help create a constituency for an invigorated program of priority nutrition interventions as well as for a more focused, well-rounded, effective, and ultimately less-expensive feeding program.

\section{Management Problems}

The constraints assessments identified management problems in several areas: human resources, material resources (particularly pharmaceuticals), finances, and information systems as well as in overall organization (see table 4.1 for a list with sources for the assessment). The discussion of these issues has special reference to nutrition, health, and education, but the problems are not unique to those sectors-rather, they encompass many elements of the public sector in Bolivia. Thus, overcoming these problems with regard to nutrition will require special effort and leadership, but success in an area of such importance to people's lives can pave the way to new directions in other areas of public service as well.

\section{Human Resources}

The most pervasive human resources problem is a weak sense of professionalism in the public service. The policy of sending recent medical graduates to the countryside for a year generates high health staff turnover and undermines the development of commitment. Worse is the overall nonprofessional nature of appointments. Political factors, not job requirements or qualifications, often determine who gets hired for even low-level positions. These human resource problems are exacerbated by a supervisory staff that is too small and is devoted more to policing than to supporting quality and client-oriented work.

Staff members who would rather work in the city are often disrespectful of poor and rural clients and may not even speak the predominant indigenous language. Many of the displaced city dwellers lack motivation in their work-teachers who arrive late Monday for school and leave early on Fridays. This lack of commitment was expressed in the MnCA as "dar por cumplir" (just going through the motions). Low pay scales also drive many public employees into sideline private practices, and strikes by public employees are all too common.

Training is held in contempt by many because it takes people out of their jobs, is not job-related, and is said to be subject, like hiring, to political favoritism. But good job-based training is an essential part of any effective program. In the case of nutrition, 
in-service training is absolutely required because pre-service medical training in nutrition is weak. The best approach to training is to build it around the job description of the person being trained, make it skills based, include the supervisor in the training, and follow-up with supportive supervision.

\section{Management of Pharmaceuticals}

The logistics system of the health sector is in dire straits. The MnCA provides detailed evidence of poor stocking, storage, distribution, and presentation of micronutrient supplements. The tracking system, information system at the delivery end, and systems for reordering supplies also appear to be flawed. Given the logistical problems in the public sector, the private sector should be tapped to handle the functions, particularly for community-based sales or distribution of iron supplements.

\section{Financial Management}

Budgeting and spending problems are ubiquitous in the government. The budgeting process is long and often unrelated to final resources available. Even though donor programs often require additional spending for transport, educational materials, and training, these line items are often not budgeted and thus the programs are underfunded. Information systems do not allow managers to track their expenditures, and disbursements are slow because of the weaknesses in accounting.

\section{Information Management}

Information on program budgets, implementation, coverage, and results is unavailable, and the information that does exist is often not collected in a reliable way. The system is beset by too many forms to fill out, of unknown purpose, which do not collect useful data.

The SNIS (Sistema Nacional de Información en Salud), for example, does not reveal coverage because it is not a population-based system but rather a client-based system. Nor does the SNIS report data on iron supplementation for young children. Estimates for ordering micronutrients (iron supplements for pregnant women or for vitamin A capsules of various doses) are apparently made on the basis of historical and unvalidated guesses about the number of pregnant women or children. As a result, too many drugs go to some clinics and health areas, while others come up short.

Managers do not set quantitative goals for nutrition programs, and no one monitors the programs' performance-not with the information system nor in any other way. Detection and treatment of diarrhea and ARI are emphasized to the detriment of other health problems because they are in the information system with goals on which resources are contingent.

\section{General Management}

Most nutrition programs in Bolivia lack concrete, quantitative, time-bound goals that are articulated and shared among staff and reflected in budgetary allocations. The division of labor among agents is ambiguous, related programs (health and water, for 
example, or agriculture and nutrition education) are not coordinated, and accountability for outcomes does not exist.

Nutrition programs enjoy little continuity from administration to administration; in consequence donors have a strong but uncoordinated influence on resource allocations, and unfortunately, nutrition has a low priority among donors. In addition, such decisionmaking as exists is centralized and thus prevents the development of teamwork and internal communications and fosters punitive supervision. These management problems are not unique to nutrition; but they are more serious for nutrition because that field is so weak in terms of human resources, organizational framework, and leadership.

One program stands out as an example of good management and organizationthe iodine program, which operated from 1981 to 1999 . It had a clearly articulated vision that was shared by the staff; a clear strategy to achieve quantitative, time-bound goals; adequate financial and material resources; and efficient work practices (the program worked through a major trader to force uniodized salt off the market). The program's organizational strength is all the more remarkable because its institutional home changed names five times in the 1990s and it changed top leadership six times (Daza, 2000 and Rocabado Quevedo,

PAN (Programa de Atención a Niños y Niñas menores de 6 años), the early-childhood development program, is also a notable success, although it has some weaknesses. Like the iodine-program, it has gone through significant bureaucratic shuffling, yet it manages to deliver high-quality services to a significant number of children. Responsibility and accountability are clearly assigned in PAN, a vision is shared by the leadership and staff (although somewhat loosely-it is not sufficiently well specified), and the financial, human, and material resources are adequate. Among the managerial weakness in PAN have been over-centralized decision making, lack of training materials, and a lack of participation of beneficiaries in program implementation and evaluation.

The major problem with PAN, however, has been that it has resulted in dependency on the part of the parents. Although the original idea of the program was to strengthen-rather than supplant-parents, PAN provides enough food for parents to simply stop feeding their children at home, and at the same time it provides too little nutrition education. The unit costs of the program are unsustainably high because of high food costs. A shift of strategy is taking place in PAN, however. Much of the food is provided by the World Food Program, which is shifting its focus away from the urban program and toward the countryside with a new, "indirect" approach. The new approach trains parents in nutrition and psychosocial needs of their children. If this program were tied into a community-based preventive health and nutrition program, it could have enormous impact at relatively. low cost. Nonetheless, by improving parenting and feeding behavior, this strategic shift for PAN promises to direct it not only toward its original purpose but also more toward the most critical nutrition issues, even though the program's focus will continue to include children older than two. 


\section{The Leadership Vacuum}

Early in the process of discussing and carrying out this study, the World Bank sponsored three one-day seminars to present the proposal and get feedback independently from three groups: government, donors, and NGOs. At the top of everyone's list of issues was the lack of leadership in nutrition. The word "leadership," however, has different meanings for different people. To some, leadership is institutional, conferred by law (de jure leadership). To others, leadership is charismatic, personal, subjective, and spontaneous (de facto leadership).

In contrast to both the de jure and de facto forms of leadership is a more practical and effective form-functional leadership. A functional leader articulates a concrete vision. The vision:

- defines the program's clients,

- defines what services it provides to them,

- sets high standards of practice, and

- gives a clear statement of where the program is today and where it needs to be at a fixed date in the future.

If functional leadership (Ohrbach, 2000) is developed, it will:

- Articulate a concrete vision for nutrition

- Establish clear, time-bound, quantitative, realistic goals

- Develop and implement a practical strategy to achieve those goals

- Mobilize resources to match the activities and goals

- Develop the right quality, quantity, and skills of staff

- Assure that all key management positions are filled and that managers share the vision

- Establish accountability for results.

Examples abound of an organization being given de jure leadership in some aspect of nutrition but failing to create functional leadership. As long as party politics dominates the civil service and so long as administrations fail to continue the good policies of their predecessors, functional nutrition leadership in Bolivia must come from the civil society and exercise what is termed in Bolivia "social control" over nutrition-related programs of the government. 
Table 4.1: Implementation Issues in Nutrition Programs

\begin{tabular}{|c|c|c|}
\hline Issue & Institution & $\begin{array}{c}\text { Source of } \\
\text { Information* }\end{array}$ \\
\hline \multicolumn{3}{|l|}{ General Structura//Institutional Issues } \\
\hline $\begin{array}{l}\text { Lack of champion for nutrition within mainstream health } \\
\text { services; agricultural services, education. }\end{array}$ & Government & $1,4,6$ \\
\hline Projects too short and small scale (NGOs) & NGOs/church & 1 \\
\hline $\begin{array}{l}\text { No clear division of labor between central, departmental and } \\
\text { municipal levels for execution, supervision and monitoring and } \\
\text { evaluation of programs in MOH, MEC, M. Ag. }\end{array}$ & $\mathrm{MOH}, \mathrm{MEC}, \mathrm{Min}$. Ag. & $2,3,6$ \\
\hline $\begin{array}{l}\text { Lack of nutritional goals and absent evaluation of nutrition in } \\
\text { nutrition-related programs 'food security, water and sanitation, } \\
\text { health) }\end{array}$ & Government & 1,5 \\
\hline Lack of operational goals & Government & 5 \\
\hline $\begin{array}{l}\text { Gender-typing: women get nutrition and social programs while } \\
\text { men get productive programs. }\end{array}$ & Government & 1,3 \\
\hline $\begin{array}{l}\text { Few well-trained nutritionısts in service; lack of staff capacity } \\
\text { (inexpenenced, deficient professional education) }\end{array}$ & $\begin{array}{l}\text { Government, Municipalities, } \\
\text { Donors, some NGOs }\end{array}$ & $1,2,3,4,6$ \\
\hline Budget cuts & Min. Finance, donors & 5 \\
\hline Lack of well defined structure for nutrition & Government & 6 \\
\hline No legal status for CIIAN & Primera Dama & 6 \\
\hline Red tape and bureaucracy & PAN, HAM, MOH, FIS, FDC & 1,2 \\
\hline Lack of employment; unreliable employment; & Min. Finance, Private Sector & $1,9,10$ \\
\hline $\begin{array}{l}\text { Difficult access to services and markets due to bad roads, long } \\
\text { distances, culture and language, gender. Lack of extension to } \\
\text { remote communities. }\end{array}$ & Government, private sector, & 1 \\
\hline Centralızed decision-makang & Government & 5 \\
\hline Lack of monitoring, info systems & Government & $1,2,5$ \\
\hline $\begin{array}{l}\text { Information system - missing indicators, not used for decision } \\
\text { making, sent to La Paz for inaction, not seen as useful by } \\
\text { personnel, late and carelessness in filling out }\end{array}$ & Government & $1,3,5,6$ \\
\hline Supervision - absent, punitive, without tools & Government & $1,2,4,5$ \\
\hline Lack of public information on programs & Government & 1,2 \\
\hline Inadequate extension to the community & Government & $1,2,3,5$ \\
\hline Misdiagnosis of the nutrition problem & $\begin{array}{l}\text { Agriculture, Food Aid, } \\
\text { Politicians, Donors, Senior Policy } \\
\text { Makers, opinion leaders, } \\
\text { (church?) }\end{array}$ & 1,5 \\
\hline $\begin{array}{l}\text { Lack of beneficiary participation in definıng problem and/or } \\
\text { solutions }\end{array}$ & Government, municipalities & 1,2 \\
\hline No baselines; no impact evaluations & NGOs, government & 3,5 \\
\hline Local counterpart financing absent/low & $\begin{array}{l}\text { Min. Finance } \\
\text { Municipalities } \\
\end{array}$ & 2 \\
\hline Excessive reliance on food handouts & Government, Donors, NGOs & 1,2 \\
\hline $\begin{array}{l}\text { Little attention to basic causes of nutrition (poverty, risk, } \\
\text { environmental degradation) }\end{array}$ & Government, donors, NGOs & 1 \\
\hline Reimbursement slow from state. & Government & $1,2,4$ \\
\hline $\begin{array}{l}\text { Lack of integration/coordination between productive activities } \\
\text { and nutrition education; among relevant sectors (water, health, } \\
\text { agnculture, education, PAN) at national and local level. }\end{array}$ & $\begin{array}{l}\text { Government, municipalities, } \\
\text { many NGOs }\end{array}$ & $2,3,4$ \\
\hline $\begin{array}{l}\text { Food (and micronutrients) programs not accompanted by } \\
\text { financing for complementary activities (nutrition education, } \\
\text { health services) and additional transport costs. }\end{array}$ & Donors & $1,2,4,5$ \\
\hline
\end{tabular}




\begin{tabular}{|c|c|c|}
\hline Issue & Institution & $\begin{array}{c}\text { Source of } \\
\text { Information* }\end{array}$ \\
\hline \multicolumn{3}{|l|}{$\begin{array}{l}\text { General Structural/Institutional Issues Specific to } \\
\text { MOH }\end{array}$} \\
\hline $\begin{array}{l}\text { Lack of training for health personnel; training not based on adult } \\
\text { learning models, not practical; requires absence from job; no } \\
\text { budget for travel and per diems; lack of transparency in selecting } \\
\text { trainees; no nutrition-specific training }\end{array}$ & $\mathrm{MOH}$ & $1,2,3,5$ \\
\hline $\begin{array}{l}\text { Growth promotion absent; SVEN only weighs children (no } \\
\text { counseling, no analysis of curve). }\end{array}$ & $\mathrm{MOH}$ & $2,3,5$ \\
\hline $\begin{array}{l}\text { Inadequate diffusion of norms or disregard of norms; inadequate } \\
\text { numbers of copies made; inadequate updating through paper and } \\
\text { trauning }\end{array}$ & $\mathrm{MOH}$ & 2,3 \\
\hline $\begin{array}{l}\text { Staffing upside-down ( } 2 \text { administrators for each operative } \\
\text { person) results in overwork of operational staff. }\end{array}$ & MOH & 2 \\
\hline $\begin{array}{l}\text { Training is done by cascade method, is theoretical and didactic; } \\
\text { insufficient and without follow-up in supervision. }\end{array}$ & $\mathrm{MOH}$ & 1,2 \\
\hline $\begin{array}{l}\text { Only growth "monitoring" available is done in clinics and is } \\
\text { focused on weighing and graphing weight;-lack of materials and } \\
\text { methods for counseling. Lack of growth "promotion." }\end{array}$ & MOH & 1,3 \\
\hline Not enough copies made of printed material & MOH & 2,3 \\
\hline Bureaucratic decision making. & PAN, MOH & 2,5 \\
\hline \multicolumn{3}{|l|}{ Targeting } \\
\hline Targeting to non-poor & Agriculture & $3,5,8$ \\
\hline Targeting to non-vulnerable & Health, PAN & $1,3,5$ \\
\hline \multicolumn{3}{|l|}{ Human Resources Issues } \\
\hline $\begin{array}{l}\text { Political appointments; lack of selection based on competence. } \\
\text { Political deviation of supplies. Lack of job security. }\end{array}$ & Government and NGOs & $1,2,3,5,6,7$ \\
\hline Lack of shared vision by staff & MOH, PAN & 5 \\
\hline $\begin{array}{l}\text { High rotation of personnel (año de provincia; political } \\
\text { appointments). Doctors are too young and inexperienced (año de } \\
\text { provincia). }\end{array}$ & $\mathrm{MOH}$ & $1,2,3,5,6,7$ \\
\hline Personnel don't speak local language & Health & $1,2,5$ \\
\hline Public Employee Strikes & Unions, sindicatos & 6 \\
\hline Disrespectful treatment of clients & $\begin{array}{l}\text { Ministry of Health and Cajas de } \\
\text { Salud }\end{array}$ & 1,2 \\
\hline $\begin{array}{l}\text { Low priority of nutrition/micronutrients; lack of knowledge of } \\
\text { importance, nutrition not mainstreamed in health personnel }\end{array}$ & Health, & $1,2,5,7$ \\
\hline $\begin{array}{l}\text { Lack of effective nutrition counseling messages and materials; } \\
\text { lack of understanding of behavior change model (but FADU is } \\
\text { excellent);. }\end{array}$ & MOH, NGOs & $1,2,3,4,5,6$ \\
\hline $\begin{array}{l}\text { Attitude of medical personnel; excessive emphasis on curative } \\
\text { care and inadequate attention to prevention and outreach. }\end{array}$ & Medical professionals & $1,2,3$ \\
\hline Nutrition low priority among health personnel & MOH & $1,2,4,5,6$ \\
\hline \multicolumn{3}{|l|}{ IEC } \\
\hline $\begin{array}{l}\text { Misinformation and erroneous ideas of personnel concerning } \\
\text { nutrition (breastfeeding, weaning, diet, micronutrients) }\end{array}$ & MOH, NGOs & 1 \\
\hline $\begin{array}{l}\text { Lack of effective nutrition counseling messages and materials; } \\
\text { lack of understanding of behavior change model (but FADU is } \\
\text { excellent); lack of "IEC"; no supporting tools; lack of } \\
\text { "promotion" of the program (by radio, e.g.). }\end{array}$ & MOH, NGOs & $1,2,3,4,5,6$ \\
\hline Lack of diffusion of Seguro Básico de Salud & $\mathrm{MOH}$ & 1,2 \\
\hline Lack of political support for breastfeeding campaign. & Donors, private industry, culture & 5 \\
\hline $\begin{array}{l}\text { Content and process of nutrition education poor. Persistent } \\
\text { insistence on milk, meat, and eggs as being essential for good } \\
\text { nutrition. Targeted only to mothers. Done only in groups, not } \\
\text { personalized. Materials not available in native languages; } \\
\text { materials largely unavallable. Clients don't understand, it's } \\
\text { Irrelevant, or boring. }\end{array}$ & $\mathrm{MOH}, \mathrm{NGOs}$ & $1,2,4,5$ \\
\hline
\end{tabular}




\begin{tabular}{|c|c|c|}
\hline Issue & Institution & $\begin{array}{c}\text { Source of } \\
\text { Information* }\end{array}$ \\
\hline \multicolumn{3}{|l|}{ Health Sector } \\
\hline Lack of continuity in health policies & $\mathrm{MOH}$ & 1 \\
\hline \multicolumn{3}{|l|}{ Micronutrients } \\
\hline Inadequate dose of iron for children under two & $\mathrm{MOH}$ & 4 \\
\hline $\begin{array}{l}\text { Poor storage and conservation of MN supplements; vitamin A } \\
\text { capsules melt due to heat; sent in clear plastic bags unprotected } \\
\text { from light and heat }\end{array}$ & MOH & 2 \\
\hline $\begin{array}{l}\text { Presentation of iron tablets inadequate (in paper, loose, in used } \\
\text { antibiotics containers. }\end{array}$ & MOH & 2,4 \\
\hline $\begin{array}{l}\text { Reimbursement/resupply of MN slow both from central } \\
\text { government and from donors }\end{array}$ & $\mathrm{MOH}$ & 2 \\
\hline $\begin{array}{l}\text { Vitamin A capsules close to or past exprration date; lack of } 100 \mathrm{~K} \\
\text { IU capsules; vitamin A fortified oil unavailable }\end{array}$ & $\mathrm{MOH}$ & 2 \\
\hline Norms developed without input from field personnel & $\mathrm{MOH}$ & 2 \\
\hline $\begin{array}{l}\text { Lack of budgeting for transport of donated micronutrient } \\
\text { commodities from district to health areas; donated commodities } \\
\text { not includes in POAs; only supplies financed not the counseling } \\
\text { materials, training, or supervision. }\end{array}$ & Cajas, NGOs, MOH & 2,3 \\
\hline $\begin{array}{l}\text { Inconsistency of policies between public and private sector/cajas } \\
\text { de salud on charging for iron causes confusion and resentment }\end{array}$ & MOH/Cajas & 2 \\
\hline $\begin{array}{l}\text { Poor or non-existent economic plannıng; no POA for } \\
\text { micronutrients; lack of planning of activities }\end{array}$ & $\mathrm{MOH}$ & $2,3,4$ \\
\hline $\begin{array}{l}\text { Requirements for MN not standardized or formal; requisttions not } \\
\text { standardized; irregular supply (cajas and private have monthly } \\
\text { supply) results in oversupply and stock outages; absolute } \\
\text { quantittes of iron-folate tablets inadequate and vitamin A. }\end{array}$ & MOH & $2,3,5,6$ \\
\hline $\begin{array}{l}\text { Low use of prenatal care (and therefore prenatal iron) and of } \\
\text { child health services }\end{array}$ & MOH & $1,2,6$ \\
\hline $\begin{array}{l}\text { No coordination between nutntionists, nurses, and pharmacies on } \\
\text { logistics of MN; lack of clear division of labor in MN }\end{array}$ & $\overline{\mathrm{MOH}}$ & 2 \\
\hline Irregular distribution of supplements & $\mathrm{MOH}$ & 2 \\
\hline $\begin{array}{l}\text { "dar por cumplir" mentality; focus on official coverage not on } \\
\text { impact. }\end{array}$ & $\mathrm{MOH}$ & 2 \\
\hline $\begin{array}{l}\text { Disconnect between the implicit focus of Ministry of Health, } \\
\text { SBS, services (heavy emphasis on Iron supplementation) and the } \\
\text { budget and program of work of the nutrition group within the } \\
\text { Ministry (almost exclusively focused on iron fortification). }\end{array}$ & $\mathrm{MOH}$ & 2 \\
\hline Iron fortified flour has no advocacy in health services. & $\mathrm{MOH}$ & 2,4 \\
\hline $\begin{array}{l}\text { Lack of clear division of labor in complance enforcement of iron } \\
\text { fortified flour }\end{array}$ & MOH/departments/munieipalities & 2,4 \\
\hline Lack of monitoring compliance with iron supplementation & MOH & 2,4 \\
\hline Delayed procurement and delivery of iron tablets & $\mathrm{MOH}$ & 2,4 \\
\hline $\begin{array}{l}\text { Inadequate aggregate iron tablet supplies (faulty estimates of } \\
\text { need) }\end{array}$ & MOH, donors & 2 \\
\hline $\begin{array}{l}\text { Lack of alternative distribution systems (outside health care } \\
\text { system) for delivering iron to women and children (ACS not } \\
\text { authorized) }\end{array}$ & $\mathrm{MOH}$ & 2,4 \\
\hline $\begin{array}{l}\text { SNIS no information on \# tablets given per pregnancy or } \\
\text { puerpernum; Not verified (but inflated) coverage numbers for } \\
\text { programs. }\end{array}$ & $\mathrm{MOH}$ & 2,4 \\
\hline Absence of Jarabe de hierro in SNIS; ignorance about coverage & $\mathrm{MOH}$ & 2,4 \\
\hline Link to crecımiento y desarollo of iron program limits coverage. & $\mathrm{MOH}$ & 4 \\
\hline \multicolumn{3}{|l|}{ PAN } \\
\hline $\begin{array}{l}\text { PAN coverage low and too many older kids; not enough younger } \\
\text { kids. }\end{array}$ & PAN & 1,11 \\
\hline Parent contributions inadequate & Parents & 5 \\
\hline Bureaucratıc decision making. & PAN, MOH & 2,5 \\
\hline
\end{tabular}




\begin{tabular}{|c|c|c|}
\hline Issue & Institution & $\begin{array}{c}\text { Source of } \\
\text { Information* }\end{array}$ \\
\hline Targeting to non-vulnerable & Health, PAN & $1,3,5$ \\
\hline Mistargeting (wrong age, non-poor) & PAN, Desayunos Escolares, & 1,2 \\
\hline Disincentives for family responsibility & PAN, Desayunos Escolares, & 1 \\
\hline Lack of shared vision by staff & $\mathrm{MOH}, \mathrm{PAN}$ & 5 \\
\hline High unit costs of PAN prevent expansion & PAN & 11 \\
\hline \multicolumn{3}{|l|}{ Desayunos Escolares } \\
\hline Mistargeting (wrong age, non-poor) & PAN, Desayunos Escolares, & 1,2 \\
\hline Disincentives for family responsibility & PAN, Desayunos Escolares, & 1 \\
\hline Lack of interest in nutrition cumculum on part of MEC & MEC & 6 \\
\hline Public Employee Strikes & Unions, sindicatos & 6 \\
\hline Lack of nutrition education in schools & MOE & 1 \\
\hline \multicolumn{3}{|l|}{ Agriculture/Food Security } \\
\hline Belief that increased food production will resolve malnutrition. & Donors, Min. Ag.; NGOs & $1,9,10$ \\
\hline $\begin{array}{l}\text { Commercialization of agricultural products not viable (garden } \\
\text { programs) }\end{array}$ & NGOs, Min. Ag. & 5 \\
\hline Targeting to non-poor & Agniculture & $3,5,8$, \\
\hline \multicolumn{3}{|l|}{ Municipalities } \\
\hline $\begin{array}{l}\text { No data or unreliable data available on problems at the municipal } \\
\text { level. }\end{array}$ & $\begin{array}{l}\text { Municipalities, National statıstics } \\
\text { office }\end{array}$ & 1,3 \\
\hline Low participation of women in municipal planning. & Mayors & 1 \\
\hline Mayors politicized & Political parties & 1 \\
\hline Lack of financial transparency of munıcipality & Mayor & 1 \\
\hline \multicolumn{3}{|l|}{ Water } \\
\hline $\begin{array}{l}\text { Inadequate access to basic sanitation services; low acceptability } \\
\text { and use of sanitary facilities. }\end{array}$ & Water services & 1,14 \\
\hline Water contamination by army and mines & Army, private industry & 1,14 \\
\hline \multicolumn{3}{|l|}{ Fortification/Food Industry } \\
\hline $\begin{array}{l}\text { Avallability of unfortified alternative to fortified foods (salt, } \\
\text { flour) }\end{array}$ & Industry, $\mathrm{MOH}$ & 5 \\
\hline $\begin{array}{l}\text { Compliance enforcement of industry (legal and technical } \\
\text { constraints). Lack of reagents }\end{array}$ & MOH, Industry & $4,5,6$ \\
\hline Lack of Public Education campaign about iron-fortified flour & $\mathrm{MOH}$ & 2,4 \\
\hline \multicolumn{3}{|l|}{ Food Aid } \\
\hline Misdiagnosis of the nutrition problem & $\begin{array}{l}\text { Agriculture, Food Aid, } \\
\text { Politicians, Donors, Senior Policy } \\
\text { Makers, opinion leaders, } \\
\text { (church?) }\end{array}$ & 1,5 \\
\hline $\begin{array}{l}\text { Foreign and unacceptable foods handed out; non-local foods } \\
\text { promoted. }\end{array}$ & Government, Donors, NGOs & $1,3,5,6$ \\
\hline \multicolumn{3}{|l|}{ Clients } \\
\hline Lack of employment; unreliable employment; & Min. Finance, Private Sector & $1,9,10$ \\
\hline $\begin{array}{l}\text { Low priority of children under two in families; not seen as } \\
\text { separate being from mother. }\end{array}$ & Families & $1,3,5$ \\
\hline $\begin{array}{l}\text { Difficult access to services and markets due to bad roads, long } \\
\text { distances, culture and language, gender. Lack of extension to } \\
\text { remote communities. }\end{array}$ & Government, private sector, & 1 \\
\hline Parent contributions to PAN inadequate & Parents & 5 \\
\hline \multicolumn{3}{|l|}{ NGOs } \\
\hline $\begin{array}{l}\text { Lack of programs for indigenous communities (particularly re } \\
\text { NGOs) }\end{array}$ & NGOs & 1 \\
\hline $\begin{array}{l}\text { Few well-trained nutritionists in service; lack of staff capacity } \\
\text { (1nexperienced, deficient professional education) }\end{array}$ & $\begin{array}{l}\text { Government, Municipalities, } \\
\text { Donors, some NGOs }\end{array}$ & $1,2,3,4,6$ \\
\hline $\begin{array}{l}\text { Lack of budgeting for transport of donated micronutrient } \\
\text { commodities from district to health areas; donated commodities } \\
\text { not includes in POAs; only supplies financed not the counselıng } \\
\text { maternals, training, or supervision. }\end{array}$ & Cajas, NGOs, MOH & 2,3 \\
\hline
\end{tabular}




\begin{tabular}{|l|c|c|}
\hline \multicolumn{1}{|c|}{ Issue } & \multicolumn{1}{c|}{ Institution } & $\begin{array}{c}\text { Source of } \\
\text { Information* }\end{array}$ \\
\hline $\begin{array}{l}\text { Lack of effective nutrition counseling messages and materials; } \\
\text { lack of understanding of behavior change model (but FADU is } \\
\text { excellent); lack of "IEC"; no supporting tools; lack of } \\
\text { "promotion" of the program (by radio, e.g.). }\end{array}$ & MOH, NGOs & $1,2,3,4,5,6$ \\
\hline
\end{tabular}

\section{Source Notes:}

1. Apreciación de Intervenciones Existentes

2. Estudio sobre la Implementación de Los Programas de Suplementación con Micronutrientes en el Sistema Nacional de Salud.

3. Evaluación Intermedia del PSF.

4. Programa de Prevención y Control de la anemia por deficiencia de hierro. Evaluación de medio Término

5. Estudio Revisión de Programas Nutricionales en Bolivia 1990-1999

6. Análisis Institucional de la Nutrición en Bolivia 1989-1999.

7. Bolivia Public Expenditure Review, 1999.

8. Rural productivity study

9. EU sources of income study 1

10. EU sources of income study 2

11. Consultations with the Poor. Bolivia Case Study. Background materials. 1999. World Bank.

12. Midterm Evaluation of PAN.

13. Meresman, S. Estudio Regional Sobre Salud y Nutrición Escolar en América latina y el Caribe. Informe Preliminar Bolivia y El Salvador. Mayo 1999.

14. Lovon water paper. 



\section{Conclusions and Recommendations}

Malnutrition is so widespread and severe in Bolivia that it threatens to handicap one-fourth of the current generation of children as well as the future economic growth of the country. Malnutrition is a cause as well as a consequence of poverty. Policies to create jobs and raise the income of the poor are critical in any long-term solution to malnutrition, but malnutrition requires specific action as well. It is found where there is income poverty as well as a poverty of access to public services and a poverty of knowledge.

Thus, solving the malnutrition problem of today's infants as well as tomorrow's requires well-targeted nutrition programs, particularly those that empower families to optimize child nutrition with their own resources. Children under two years of age and pregnant women are the most affected by the problem and the most likely to suffer irreversible consequences. Iron deficiency anemia in particular is severe, affecting twothirds of children under two and more than one-fourth of pregnant women.

\section{The Weaknesses of the Nutrition Response}

The nutrition problem is generally misdiagnosed in Bolivia, where it is seen, by and large, as a food production problem, a women's problem, and a medical problem. In fact, the nutrition problem is more complex and more specific, and resolving it will require addressing both a "supply-side" and a "demand-side" problem. On the supply side, high-quality nutrition services, including fortified foods, supplements, growth monitoring of infants, and behavior-oriented interventions must be made accessible to the poor, particularly children under two and pregnant women, at the community level. The quality of services and human rèsources must be improved.

On the demand side, greater attention must be paid to the motivations, beliefs, and constraints of poor families with respect to the growth and development of young children and the well being of pregnant women. At the same time, the informed demand by civil society for an adequate response to malnutrition is critical to assure sustained public support for targeted nutritional interventions. The inadequacy of the current response to malnutrition can be encapsulated in three points:

First, the budget analysis and inventory show that the poor and highest risk populations are not targeted adequately. Fewer than 10 percent of government and NGO nutrition-related dollars are spent on efficient nutritional interventions serving poor pregnant women and malnourished children under two. Feeding programs (PAN, school breakfast, and the subsidy for pregnant and lactating women) are generally not thought to be efficient, yet they absorbed more than half of all "direct nutrition" spending in 2000 .

Feeding programs are not only the most expensive type of nutrition program available (with the least evidence of impact), but they maintain the paternalistic 
relationship between the government and beneficiaries and divert attention from sustainable, empowering approaches to nutrition such as productive investments, employment generation, and communications for behavior change.

Second, the poor have insufficient access to the services they need to overcome malnutrition. Most nutrition and food security programs depend on families having access to health care, agriculture extension services, clean water and proper sanitation, and markets, yet those at greatest risk have least access to such resources.

Third, the participatory process is failing to address malnutrition. Few, if any, public programs are community based or even reach poor communities. The Popular Participation process, even in the model municipalities (Mizque, for example), which might be seen as "community based," has yet to come to grips with the nutrition problem per se and the participatory decision-making that gives voice to the poor, to women, and to indigenous families. Participants lack the relevant information about the nature of malnutrition (who is affected and why), the capacity to analyze local information, and knowledge of efficient solutions. The ineffectiveness of development projects is due in part to a lack of participation by the poor in problem diagnosis, project design, monitoring, and evaluation.

The broader context for the failed response to malnutrition is a lack of functional leadership. No individual or entity is accountable for nutrition results either to the President, the Congress, the donors, or civil society. The lack of leadership has blocked the development of a clear vision of the nutrition problem and its solutions, a vision that must be shared by the government, NGOs, donors, local government, and the people most affected by malnutrition. Hence no practical strategy exists for addressing malnutrition overall or even in any sector. The absence of such vision has led to the funding of short-term, simplistic, inappropriate, and expensive programs and to the lack of coordination and synergies at the local level. The nutrition programs do not reflect international best practice and are not likely to get much nutritional bang for the buck.

In sum, a large amount of money is being spent on nutrition-related programs without evidence of proper management during implementation or measurement of results. Without an adequate information system or evaluations, it is impossible to say whether or not this money is reaching the poor and making an impact but much evidence suggests it is not reaching the poor and vulnerable. Until existing resources are better allocated to groups in greatest need and to efficient interventions, no new resources should be added for nutrition programs.

Solving the nutrition problem will require measured actions by the government, donor support and careful supervision over many years. The basic building blocks of an effective nutrition strategy are available but need to be improved and better coordinated both at the national strategic level and at the local planning and implementation level. 


\section{General Recommendations}

- A national nutrition vision must be developed.

5.12 The government, in collaboration with civil society, should develop and articulate a concrete vision for addressing malnutrition, including quantitative time-bound goals, program priorities, and resource requirements. This should be facilitated by a disinterested organization or individual.

\section{- A national nutrition education strategy must be developed.}

A national sensitization and education strategy would educate the general public, policymakers, and various segments of the population about nutrition in general. In addition, an operational nutrition education strategy would be incorporated into sectoral programs. The strategies would be based on good communications and marketing principles and consist of feasible solutions developed and tested in poor communities. Interpersonal communications are essential and should be carried out by community-based agents in almost every sector. Messages tailored to the specific needs of each individual and negotiation between counselor and caregiver on incremental behavioral changes are key to effective interpersonal nutrition counseling. Each sectorparticularly health, education, PAN, and agriculture-should have a coherent sectoral nutrition education strategy (both for clients and for staff) that is consistent with the overall national strategy. Mass media should be used judiciously to reinforce interpersonal communications.

\section{- The tremendous potential of the municipal planning process needs to be harnessed for nutrition.}

Municipal governments need to be strengthened in their capacity to undertake analysis, design, implementation, and evaluation of nutrition-related programs. Technical assistance to the municipalities and their planning committees is absolutely critical for the future of nutrition in Bolivia. Tools available in nutrition (like growth performance of children) can be used for diagnosing problems, planning, targeting resources, and evaluating impact. Existing human resources-departmental nutrition staff in the Ministry of Health and the PAN-should be trained and redeployed to provide technical assistance to municipalities.

- NGOs, religious organizations, and the government need to pool resources and agree upon an efficient division of labor.

Government organizations, including municipalities, as well as the church and civil society need to agree upon how they are going to work together if resources are to be used most efficiently and if gaps, overlaps, and conflicts among programs are to be 
avoided. If civil society is to continue as the agent of "social control," the implementation and evaluation functions of nutrition programs must be separated.

- The Ministry of Health and Social Provision could make special efforts that would greatly improve nutrition services provided through the public health system and NGOs.

The Ministry of Health (MOH) must work to mainstream nutrition in basic services, the Seguro Básico de Salud, the Health Reform, epidemiological surveillance, information systems, and goals of the other ministries; and the MOH should guide NGOs working on nutrition in Bolivia on where to work, the need to conform to MOH norms, and the desirability of collaborating on extension at the community level. These actions may best be executed by giving one individual and one unit in the MOH responsibility for nutrition advocacy and coordination (not for the operation of nutrition programs) and providing to that person the resources to fulfill the mandate.

The recently negotiated Health Reform APL loan Phase II has incorporated community-based growth promotion into the set of activities to be financed by the loan. Close supervision and technical support will be needed to assure the successful implementation of this component.

- More and better nutritionists must be trained, and the training of doctors and nurses must be expanded to incorporate nutrition.

The expansion of nutrition education and the reform of medical education in Bolivia would have a big influence on the future performance of nutrition programs and the health sector. Doctors and nurses are poorly informed about nutrition, and the supply of well-trained practical nutritionists is far too small. The training must be practical, prevention-oriented, and directed at the problems and populations seen in a public program setting.

\section{- The cost and impact of nutrition programs must be tracked.}

Cost and impact data should be collected for all nutrition programs, not only because the PRSP has established goals for nutrition but also because responsible financial management demands it. These data should be used for decision-making about resource allocation and to identify areas for management improvement. A functional program information system (which provides up-to-date data on coverage, costs, and disaggregated expenditures on such things as training, IEC, supervision, and logistics) coupled with objective and rigorous impact evaluation is also needed. Coverage and participation of high-priority population groups (extremely poor children under two and pregnant women) are also crucial for evaluation. 
- School feeding programs need revamping. The first step is to recognize the programs as education investments and integrate them into educational planning and resource allocations.

To maximize educational impact, school feeding must be redesigned and retargeted. Targeting needs to be based on educational and food security factors, and the food ration must meet nutritional and food safety standards on the basis of the minimum cost and nutritional value necessary to achieve goals. Unit costs must be standardized and controlled across programs. Consistent data on all school feeding programs must be collected through a single information system, regardless who manages the various programs. A clear division of labor needs to be established among the Ministries of Health and Education, the municipalities, the First Lady's Office, NGOs, and food aid donors. While execution needs to be decentralized to the lowest level, normative and cost control must be exerted from a higher level. The Ministry of Education needs to mainstream school feeding within its overall strategy for improving participation in, and the efficiency of, schooling. The MOH needs to work closely with the MOE and municipalities to establish standards and supervise and evaluate the program.

- Programs for roads, water, agriculture, credit, employment, and family planning address the underlying causes of malnutrition; they should be targeted to poor households and their impact on malnutrition should be measured.

Ideally these programs would also include a nutrition education component or coordinate with local nutrition education programs. Tracking outcomes and evaluating nutritional impacts is critical to supportive programs, such as rural development and water and sanitation initiatives. And the closer these interventions are coordinated with other related initiatives, the more likely they are to be effective.

- Once a strategic plan is articulated by Bolivia, the international community should unify behind it and provide the necessary technical and financial resources over a sufficiently long period to implement it.

Much is demanded of Bolivia to address its severe problem of malnutrition. The international community owes Bolivia its support if the country marshals the political will to meet the challenge.

\section{An Action Plan for 2003-4}

The Bolivian government, society, and international community could take the following seven concrete actions to improve nutrition within the next year:

\section{Name leaders to develop nutrition vision and strategy.}

One or more credible leaders must be appointed to develop a concrete vision and strategic plan for nutrition. These leaders should be chosen on the basis of commitment 
to nutrition and management ability, not on the basis of party affiliation. The vision should provide clear guidelines for all levels of government and a clear allocation of responsibility among stakeholders. It should reflect widespread agreement among stakeholders.

\section{Develop nutrition education focused on the high-priority population.}

The Ministry of Health should develop a coherent national nutrition education strategy based on social marketing principles. It should be focused on behavior change, with messages developed in collaboration with poor families based on trials of improved practices. The strategy focus first on the child from birth to two years old and the pregnant and lactating woman. The preliminary work for this will be financed by the recently approved Health Reform APL loan, Phase II.

\section{Create a private commission to demand continuity of government attention to nutrition.}

The commission should consist of influential members of Bolivian society (including private industry, the Church, academia, foundations, the media, and social action groups). It would review progress in policies, programs, impact, and financing and report to the public. Its primary purpose would be to assure transparency about goals, progress, costs, and benefits. Financial support must be provided in such a way to ensure objectivity.

\section{Improve iron supplementation.}

The Ministry of Health should address the management problems identified in the Micronutrient Constraints Assessment concerning the iron supplementation program.

\section{Invest in municipalities.}

Provide 25 to 30 municipalities with technical assistance in nutrition analysis and action-including how to assure the full participation of poor women-to develop a nutrition investment plan for 2003.

\section{Develop community-based nutrition programming.}

PAN and MSPS should develop a model community-based nutrition program focused on growth promotion and derived from the Modalidad Indirecta in the PAN program.

\section{Make nutrition status an indicator of program success.}

Over the next year the government, with international cooperation, should put in place a monitoring system that includes nutrition status as a key outcome indicator for the PRSP and for interventions in water and sanitation, roads, education, health, and agriculture. 
These actions are all high priority but some high level action and longer time. Some of these are already being implemented. In order to prioritize, some very rough estimates of cost are presented below.

\begin{tabular}{|c|c|c|c|}
\hline Action & Responsibility & Cost & $\begin{array}{l}\text { Currently under } \\
\text { implementation? }\end{array}$ \\
\hline $\begin{array}{l}\text { 1. Name nutrition } \\
\text { leaders }\end{array}$ & Presidency & $\$ 50,000$ per year & No \\
\hline $\begin{array}{l}\text { 2. Develop nutrition } \\
\text { education strategy }\end{array}$ & Minister of Health & $\$ 1$ million & Yes \\
\hline $\begin{array}{l}\text { 3. Create private } \\
\text { watchdog } \\
\text { commission }\end{array}$ & $\begin{array}{l}\text { President and civic } \\
\text { leaders }\end{array}$ & $\begin{array}{l}\$ 10,000 \text { plus } \\
\text { private sector } \\
\text { contributions }\end{array}$ & No \\
\hline $\begin{array}{l}\text { 4. Improve iron } \\
\text { supplementation }\end{array}$ & Minister of Health & $\$ 500,000$ & Yes \\
\hline $\begin{array}{l}\text { 5. Technical } \\
\text { assistance to } 25 \\
\text { municipalities }\end{array}$ & $\begin{array}{l}\text { Minister of Popular } \\
\text { Participation }\end{array}$ & $\$ 250,000$ & No \\
\hline $\begin{array}{l}\text { 6. Develop } \\
\text { community-based } \\
\text { program }\end{array}$ & $\begin{array}{l}\text { Minister of Health } \\
\text { and Director of } \\
\text { PAN }\end{array}$ & $\$ 5$ million & Yes \\
\hline $\begin{array}{l}\text { 7. Measure nutrition } \\
\text { status in ENDSA } \\
\text { and LSMS surveys }\end{array}$ & $\begin{array}{l}\text { Minister of } \\
\text { Finance/UDAPE }\end{array}$ & $\begin{array}{l}\$ 100,000 \text { per } \\
\text { survey }\end{array}$ & No \\
\hline
\end{tabular}

As these actions are taken, improved monitoring and financial management are needed so that Bolivia can track its progress and measure results. 



\section{References}

Alderman, H., J.R. Behrman, V. Lavy, and R. Menon. Child health and school enrollment: a longitudinal analysis. J. Human Resources (forthcoming, 2000).

Anderson, M.A. 1981. Health and nutrition Impact of Potable water in Rural Bolivia. J. Trop. Ped 27, 39-46.

Barker, D.J.P., and C. Fall. 1985. The immediate and long-term consequences of low birthweight. Paper prepared for World Bank/UNICEF Conference on Low Birth Weight, March 2000, New York. M.C. McCormick.

Behrman, J.R. 1996. The Economic Rationale for Investing in Nutrition in Developing Countries." World Development 21, no. 11: 1749-71, 1993.

Behrman, J.R. 1996. The impact of health and nutrition on education. World Bank Research Observer 11(1): 23-37.

Behrman, J.B., and B.L. Wolfe. 1984. More evidence on nutrition demand: income seems overrated and women's schooling underemphasized. J. Devel. Econ. 14: 105128.

CARE. 1996. Diagnóstico Rápido, Seguridad de los Medios de Vida de la Unidad Familiar en la Zona Alta del Rió Chico.

Cariaga \& Cariaga. 1996. Lineamientos para una estratégia de seguridad alimentaria. Informe preparado para la Secretaria Ejecutiva de PL 480. La Paz, Bolivia: photocopy.

Carr, D., D.R. Gwatkin, D. Fragueiro, and R. Pande. 1999. A guide to country-level information about equity, poverty and health available from multi-country research programs. HNP Paper Series. Washington, DC: World Bank.

Centro de Estudios \& Proyectos, S.R.L. 1998. Pobreza, Genero y Medio Ambiente (case studies for Cochabamba, Chuquisaca, Potosi, and Tarija. La Paz, Bolivia: Muela del Diablo.

Comisión Europea, Unidad de Seguridad Alimentaria. Feb. 2000. Household Income Strategies and Food Security Interventions in the Bolivian Highlands. Apuntes Tecnicos No. 2. La Paz, Bolivia. Delegación de la Comisión Europea.

Comisión Europea, Unidad de Seguirdad Alimentaria. Sept. 2000. La Economía Rural en Bolivia: Estructura de Empleo, Composición de Ingresos e Integración al Mercado. Apuntes Técnicos No. 3. La Paz, Bolivia: Delegación de la Comisión Europea.

Comisión Europea, Unidad de Seguridad Alimentaria. Dic. 2000. Mercados Agroalimentarios en Bolivia: El caso de Arroz, Maiz, Trigo y Papa. Apuntes Técnicos No. 4. La Paz, Bolivia: Delegación de la Comisión Europea

CONALSA/FAO. 1997. CIESA (Carpeta Ejecutive de Informacion Básica sobre Seguridad Alimentaria). La Paz, Bolivia: CONALSA and FAO. 
Davalos, A., and R. Dulon. 1999. Fuentes y Niveles de Ingresos de Familias Rurales en Riesgo de Inseguridad Alimentaria. EU/Unidad de Seguirdad Alimentaria. La Paz, Bolivia: photocopy. (EU2 study).

Daza, G. 2000. Estudio Revisión de Programas Nutricionales en Bolivia 1990-1999. Draft report prepared for the Poverty and Nutrition Study.

Daza, G., and D. Alvarez Gantier. 1999. Programa de Prevención y Control de la Anemia por Deficiencia de Hierro. Evaluación de Medio Término. Programa Mundial de Alimentos, Informe Final. La Paz, Bolivia: Programa Mundial de Alimentos.

Del Rosso, J.M., and T. Marek. 1996 Class Action: Improving School Performance in the Developing world through Better Health and Nutrition. Washington, DC: World Bank (Directions in Development).

Deolalikar, A.B. 1988. Nutrition and Labor Productivity in Agriculture: Estimates for rural South India. Rev. of Econ. and Stat. 70 (3): 406-13.

Dickin, K., M. Griffiths, and E. Piwoz. 1997. Designing by Dialogue. A Program Planner's Guide to Consultative Research for Improving Young Child Feeding. Washington, DC: Academy for Educational Development.

Encuesta de Vitamina A y Encuesta de Consumo1991. Areas Deprimidas Bolivia.

Fallon, P. Oct. 2000. "Empirics of the link between growth and poverty" PREM notes. World Bank.

FAOSTAT. www.faostat. Consulted Sept. 12, 2001 for most recent data(1999).

Favin, M., and M. Griffiths. 1999. Using communication to improve nutrition. Nutrition Toolkit Tool \#9. Washington, DC: World Bank. www.worldbank.org/nutritiontoolkit

Galloway, R., E. Dusch, L. Edler, E. Achadi, R. Grajeda, E. Hurtado, M. Favin, S. Kanani, J. Marsaban, N. Meda, M. Moore, L. Morison, N. Raina, J. Rajaratnam, J. Rodriguez, and C. Stephen. 2001. Women's perceptions of iron deficiency and anemia prevention and control in eight developing countries. Soc. Sci. and Med.: forthcoming.

Gillespie, S. 1998. Major issues in the control of iron deficiency. Ottawa, Canada: Micronutrient Initiative.

Gillespie, S. August 1998. Supplementary Feeding for Mothers and Children : Operational Guidelines. Provisional. World Food Program, Rome, Italy.

Gisbert, M.E., M. Painter, and M. Quiton. 1994. Gender Issues Associated with Labor Migration and Dependence on Off-Farm Income in Rural Bolivia. Human Organization 53(2). Pp. 110-122.

Gonzalez-Cossio, T., Juan Rivera D., Mario Flores, and Wilma B. Freire. July 1997. Creciendo en las Américas: la magnitud de la desnutrición al final del siglo. PAHO, Washington, DC. 
Government of Bolivia and World Bank. May 1998. Estudio de Productividad Rural y Manejo de Recursos naturales(the "rural productivity study").

Government of Bolivia. 1982. Bolivia national nutritional status survey, 1981. National Institute for Food and Nutrition, La Paz, Bolivia.

Greksa, L.P. Growth pattern of European and Amerindian high altitude natives. 1986. Current Anthropology 27: 251-262.

Griffiths, M., K. Dickin, and M. Favin. 1996. Promoting the Growth of Children: What Works. World Bank Nutrition Toolkit, Tool \#4. World Bank.

Gwatkin, D.R., J.R. Wilcox, and J.D. Wray. 1980. Can health and nutrition interventions make a difference? Monograph 13. Washington, DC: Overseas Development Council.

Haas, J.D., et al. 1982. Altitude and infant growth in Bolivia: a longitudinal study. Am. J. Physical Anthropology. 59: 251-262.

Habicht, J.-P., R. Martorell, C. Yarbrough, R. Maloina, and R.E. Klein. 1974. Height and Weight Standards for Preschool Children. How relevant are ethnic differences in growth potential?. Lancet I(7858): 611-615.

Haddad, L., J. Hoddinott, and H. Alderman. 1997. Intrahousehold Resource Allocation in Developing Countries: Models, Methods, and Policy. Baltimore, MD: Johns Hopkins University Press.

Ho, T.J. 1985. Economic issues in assessing nutrition projects: costs, affordability, and cost-effectiveness. Washington, DC: World Bank PHN Technical Note 85-14.

INE/Macro Int'1. 1989. Encuesta Nacional de Demografia y Salud. La Paz and Calverton, MD. MACRO.

INE/Macro Int'l. 1994. Encuesta Nacional de Demografia y Salud. La Paz and Calverton, MD. MACRO.

INE/Macro Int'l. 1998. Encuesta Nacional de Demografia y Salud. La Paz and Calverton, MD. MACRO.

Jimenez, W. Determinantes de la Nutrición en Bolivia. 5/6/2001. Consultants report.

Lavadenz. 2001. Personal communication.

Levin, H.M. 1986. A Benefit-Cost Analysis of Nutritional Interventions for Anemia Reduction. PHN Technical Note 85-12. The World Bank.

López, Maria Eugenia y Juana Molina. August 2000. Estudio sobre la implementación de los programas de suplementación con micronutrientes en el sistema nacional de salud. Informe final. Consultants report. Mimeograph.

Lovon, M. July 2000. Estudio de Evaluación de impacto en aspectos de nutrición y salud. Programa de Seguridad Alimentaria Nutricional en las provincias Arque, Bolivar y Tapacari. (PROSANA). Xerox. 
Martorell, R. 1984. Genetics, environment and growth: issues in the assessment of nutritional status. In Velazquez and A, Bourges. Genetic factors in Nutrition. NY: Academic Press.

Mason, John. 16 Nov, 1999. How Nutrition Improves and What That Implies for Policy Decisions. Narrative Paper for the World Bank UNICEF Assessment.

McCormick, M.C. 1985. The Contribution of Low Birth Weight to Infant Mortality and Childhood Morbidity. New England J. Medicine. 312(2):82-90.

McGuire, J. January 1996. The Payoff from Improving Nutrition. Mimeo. World Bank.

McGuire, J.S., and J.A. Austin (1987-2). Beyond Survival: Children's Growth for National Development. UNICEF.

Mercados Agroalimentarios en Bolivia: El caso de Arroz, Maiz, Trigo y Papa. Apuntes Tecnicos No. 4, Comision Europea, Unidad de Seguridad Alimentaria. Dic. 2000.

Meresman, S. 1999. Estudio Regional sobre Salud y Nutricion Escolar en America latina y el Caribe. Informe Preliminar Bolivia y El Salvador.

Ministerio de Desarollo Económico, Secretaria Nacional de Agricultura y Ganaderia, Consejo Nacional de Seguridad Alimentaria. 1997. PLANSA: Plan Nacional para la Seguridad Alimentaria. La Paz, Bolivia: photocopy.

Moore, L.G. 2001. Human genetic adaptation to high altitude. High Altitude Medicine and Biology: $2(2): 257-279$.

National Institute for Food and Nutrition. 1982. Bolivia national nutritional status survey, 1981. La Paz, Bolivia: Government of Bolivia.

Obert, P., et al. 1994. The importance of socioeconomic and nutritional conditions rather than altitude on physical growth of prepubertal Andean highland boys. 1994. Annals Human Biology 21: 145-54.

OMNI. 1997. Conocimientos, actitudes y practicas de las embarazadas en relación a sus embarazos, el problema de las anemias, sus consecuencias y sus métodos de control. La Paz: OMNI/John Snow Inc.

OPS. 1990. Nutricion materna y productos del embarazo. Evaluación antropometrica. Publicación científica No. 529. Washington, DC: OPS.

Orbach, Eliezer. 2000. Capacity Building. Notes from WBI training course.

Paulson, S., and N. Velarde. Marzo 2001. Apreciación de Intervenciones Existentes: Estudio sobre Desnutrición y Pobreza en Bolivia. Informe Final. Consultans report. Photocopy.

Pelletier, D. 1994. A methodology for estimating the contribution of malnutrition to child mortality in developing countries. J. Nutrition 124: 2106-2122.

Pollitt, E., et al. 1996. A Reconceptualization of the Effects of Undernutrition on Children's Biological, Psychosocial, and Behavioral Development. Social Policy Report X(5): 1-21, (Society for Research in Child Development, Ann Arbor, MI). 
PROFILES. n.d. Nutrición en Bolivia. Likely date: 2000. La Prioridad en la Lucha contra la Pobreza. Photocopy.

Prudencio, J., and I. Cossio. Sept. 1998. Niveles y Fuentes de Ingreso de hogares Rurales in Riesgo de Inseguridad Alimentaria en Municipios Seleccionados (EU1 study).

Ranatunga, P. 2000. A government/non-government collaboration in poverty alleviation - with a nutrition entry. Kandy, Sri Lanka: Digital Teleprints.

Rivera A, F. 1997. Efecto de la anemia ferropriva en el lactante sobre el desarrollo psicologico del escolar. Rev. Soc. Bol. Ped. 38 (supp. 1): S49-54.

Rocabado Quevedo, F. 1991. Enseñanzas de31 Caso Boliviano en la Ejecución de Programas de Fortificación de la Sal. Case study prepared for EDI Latin America Regional Nutrition Course.

Sanghvi, T., and J. Murray. 1997. Improving child health through nutrition: The nutrition minimum package. Technical Report. Arlington, VA: BASICS.

Sara, J., A. Gross, and C. van den Berg. 1996. Rural Water Supply \& Sanitation in Bolivia: From Pilot Project to national Program. Washington, DC: World Bank.

Scholl, T.O., and M.L. Hediger. 1994. Anemia and iron deficiency anemia: compilation of data on pregnancy outcome. Am. J. Clin. Nutr. 59:492S-501S.

SCN (UN Administrative Coordinating Committee, SubCommittee on Nutrition). 1997. Third Review of the World Nutrition Situation. Geneva: SCN.

Strauss, J. 1986. Does better nutrition increase farm productivity. J. Polit. Econ. 94 (2): 297-320.

Strauss, J., and D. Thomas. 1998. Health, Nutrition and Economic Development. J. Econ. Lit. Vol XXXVI: 766-817.

Sullivan, F., L. Johnson, D. McIntyre. July 1999. Mid-Term Evaluation. FY1997-2001 Bolivia Title II Development Assistance Program. La Paz, USAID. Photocopy.

Thomas, D., and J. Strauss. 1997. Health and Wages: Evidence on Men and Women in Urban Brazil. J. Econometrics 77 (1): 277-95.

Tomkins, A., and F. Watson. 1989. Malnutrition and Infection. A Review. ACC/SCN State of the Art Series, Nutrition Policy Discussion Paper No. 5

UDAPSO/UNICEF. 1996A. Causas de la desnutrición en los niños - estudio de casos en las comunidades de Pueblo Nuevo y Terebinto, Depto de Sta. Cruz (Resumen). La Paz, Bolivia: UNICEF.

UDAPSO/UNICEF. 1996B. Causas de la desnutrición en los niños - estudio de casos en las comunidades de Otorongo, Corso, y Trampa Mayu, Depto. de Chuquisaca (Resumen). La Paz, Bolivia: UNICEF.

UNICEF. 1989. Improving Child Survival and Nutrition. The Joint WHO/UNICEF Nutrition Support Programme in Iringa, Tanzania. NY: UNICEF. 
UNICEF. 1993. We will never go back. Social mobilization in the Child Survival and Development Programme in the United Republic of Tanzania. NY: UNICEF.

USAID/VITAL/UNICEF/OPS-OMS/Ministry of Health. 1993-4. Photocopy. Prevalencia de Anemias Nutricionales. Min. de Desarollo Human, Sec. Nac. De Salud/OPS-OMS. Undated photocopy.

Van Lubek, Marianne, La Alimentación de Niños menores de cinco anos en el distrito I de la Ciudad de El Also. Proyecto de Fortalecimiento de la Atención Primaria en Salud en los Distritos I y IV de al ciudad de El Alto. Undated (but not before 1994).

Villalobos, Carlos, Judith McGuire and Magdalene Rosenmoller. 2000. Honduras. AIN-C Integrated Child Care: Improving health and nutrition at the community level. In Rosenmoller, M. editor. Challenges of health Reform. Barcelona, Spain: Estudios y Ediciones IESE-SL. (also at www.worldbank.org/lachealth).

Weinstein, H. 1999. The food fortification component of the World Bank's "Poverty and Nutrition Project: Constraints Assessment of Micronutrient Programs in Bolivia," Consultancy Report. Nov. 1999. Photocopy.

World Bank. 1994. Enriching Lives. Overcoming vitamin and mineral malnutrition in developing countries. Washington, DC: The World Bank.

World Bank. 1999. Consultations with the Poor. Bolivia Case.

World Bank. 1999A. Bolivia Public Expenditure Review. Report 19232-BO. Washington, DC: World Bank.

World Bank. 2000. Bolivia : Poverty Diagnostic. Washington, DC: World Bank.

World Bank. 2000A. ICR on a Credit in the Amount of SDR 9.6 million to the Republic of Bolivia for a Rural Communities Development Project. June 16, 2000, Report No: 20649.

Zamora, A., and S. Barrera. 1998. Rendimiento Escolar y Estado Nutricional. La Paz, Bolivia: Ministerio de Educación, Cultura y Deportes.

Zeitlin, M., M. Griffiths, R.K. Manoff, and T.M. Cooke. 1984. Vol. IV. Household Evaluation. Nutrition Communication and Behavior Change Component. Indonesia Nutrition Development Program. Jakarta and Washington, DC: Government of Indonesia and Manoff International (photocopy). 

THE WORLD BANK

1818 H Street, N.W.

Washington, D.C. 20433 USA

Telephone: 202-473-1000

Facsimile: 202-477-6391

Internet: www.worldbank.org

E-mail: feedback@worldbank.org
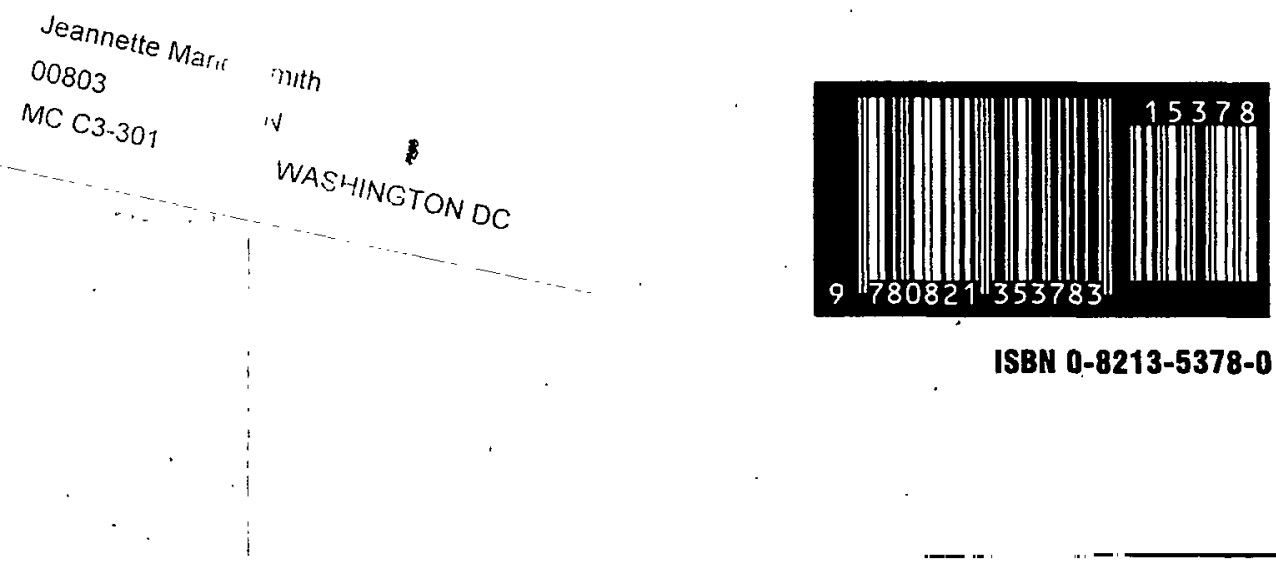

ISBN 0-8213-5378-0 